\title{
The morbid anatomy of the human genome: chromosomal location of mutations causing
}

\author{
disease (update 1 December 1993)
}

Victor A McKusick, Joanna S Amberger

A survey of the chromosomal location of mutations causing genetic disorders was published in this journal in January 1993 (McKusick and Amberger, 1993). The information presented then was complete to 1 November 1992. Here, we present information that has become available since that date, including both new assignments and revision of previous assignments. This information on the so-called morbid anatomy of the human genome is derived from a synopsis of the human gene map that has been updated continuously since 1971 as part of McKusick's Mendelian inheritance in man (10th ed, 1992) and of OMIM (online Mendelian inheritance in man, available generally since 1987).

In table 1, new information on genes that have been located to specific chromosomal positions and are also the site of disease-producing mutations is arranged by chromosome, starting with chromosome 1 and with the end of the short arm of the chromosome in each case. The new information is presented in pictorial form in the figure.

In table 2 an alphabetised list of these disorders and the chromosomal location of the mutation in each case are provided. After the name of the disorder, both in the "Disorder" field of table 1 and in table 2 , the numbers 1 , 2 , or 3 in parentheses indicate that its chromosomal location was determined by mapping of the wild type gene (1), by mapping of the clinical phenotype (2), or by both strategies (3). (In some instances, a (3) is used when the clinical phenotype has been mapped and an intragenic mutation has been identified in a candidate gene even though the wild type gene has not been independently mapped.)

The fields in the listing by chromosome (table 1) are as follows:

Location - that is, chromosomal site $(p=$ short arm; $\mathrm{q}=$ long arm; numbers = band; ter = end).

Symbol - The symbol approved by the Nomenclature Committee of the Human Gene Mapping Workshops and their successor organisation is given first; alternative symbols are included.

Status $-\mathrm{C}=$ confirmed; $\mathrm{P}=$ provisional $\mathbf{L}$ $=$ "in limbo" (that is, tentative or inconsistent). The "in limbo" entries are not included in the figure.
Title - name of gene locus

MIM\# - This is the number in McKusick's Mendelian inheritance in man (MIM, 10th ed, 1992), its continuously updated online version OMIM, and its periodically released CDROM version. (For historical reasons, the number may sometimes indicate location of the entry in the "dominant catalogue" because the wild type gene was characterised and mapped before the recessive disorder resulting from mutation at that site. The practice has been to create only one entry in MIM for each gene locus; however, for some disorders, an entry describing the phenotype, identified by a number sign (\#), and a separate entry, identified by an asterisk, for the protein affected by the mutation have been created. Marfan syndrome (154700) and fibrillin (134797) are examples; see chromosome 15.)

\section{Method of mapping}

$\mathbf{A}=$ in situ DNA-RNA or DNA-DNA annealing ("hybridisation"); for example, COL7A1 to $3 \mathrm{p} 21.32$.

C = chromosome mediated gene transfer (CMGT); for example, cotransfer of COL1A1 and thymidine kinase gene on chromosome 17.

$\mathbf{C h}=$ chromosomal change associated with particular phenotype and not proved to represent linkage $(\mathrm{Fc})$, deletion (D), or virus effect (V); for example, blepharophimosis, epicanthus inversus, and ptosis to $3 \mathrm{q} 22-\mathrm{q} 23$.

$\mathbf{D}=$ deletion or dosage mapping (concurrence of chromosomal deletion and phenotypic evidence of hemizygosity), trisomy mapping (presence of three alleles in the case of a highly polymorphic locus), or gene dosage effects (correlation of trisomic state of part or all of a chromosome with $50 \%$ more gene product). Includes "loss of heterozygosity" (loss of alleles) in malignancies. Examples: acid phosphatase-1 to chromosome 2; glutathione reductase to chromosome 8 . Includes DNA dosage; for example, fibrinogen loci to $4 \mathrm{q} 2$. Dosage mapping also includes coamplification in tumour cells.

$\mathbf{F}=$ linkage study in families; for example, linkage of ABO blood group and nail-patella syndrome. When a chromosomal heteromorphism or rearrangement is one trait, $F c$ is used; for example, Duffy blood group locus on chromosome 1 . When one or both of the
Correspondence to J S Amberger 
linked loci are identified by a DNA polymorphism, Fd is used; for example, Osler-RenduWeber disease on chromosome $9 \mathrm{q} . \quad \mathrm{F}=\mathrm{L}$ in the symbolism of the HGM workshops.

$\mathbf{H}=$ based on presumed homology; for example, Neimann-Pick disease, type $C$, on 19p. Mainly heuristic or confirmatory.

LD = linkage disequilibrium; includes homozygosity mapping, for example, familial dysautonomia.

$\mathbf{M}=$ Microcell mediated gene transfer (MMGT); for example, Bloom syndrome.

Psh = PCR of somatic cell hybrid DNA.

$\mathbf{R E}=$ Restriction endonuclease techniques; for example, physical linkage of 3 fibrinogen genes (on 4q) and apolipoprotein cluster, including APOC3 on $11 \mathrm{q}$.

REa = combined with somatic cell hybridisation; for example, gene for type VII collagen (COL7A1), which is mutant in dystrophic epidermolysis bullosa.

$\mathbf{R E b}=$ combined with chromosome sorting; for example, thyroglobulin to 8q. (For this method, using flow sorted chromosomes, W was the symbol adopted by the HGM workshops.)

REn = neighbour analysis in restriction fragments, for example, in pulsed-field gel electrophoresis (PFGE); for example, protein C inhibitor.

$\mathbf{S}=$ 'segregation' (cosegregation) of human cellular traits and human chromosomes (or segments of chromosomes) in particular clones from interspecies somatic cell hybrids; for example, GM2 ganglioside activator protein on chromosome 5 . When with restriction enzyme, REa.

Disorder - Allelic disorders are separated by semicolons. Brackets [] indicate a "nondisease", that is, a variation with no definite adverse consequences. Braces \{\} indicate specific susceptibility or resistance with monogenic basis. (1) = wild type gene mapped. (2) $=$ disease phenotype mapped. (3) $=$ both wild type gene and disease phenotype mapped (or disease phenotype mapped and mutations identified in the wild type gene).

Mouse - Mouse chromosome carrying homologous gene.

\section{Discussion}

With the additions made in the last year, a total of 928 disorders have by now been assigned to specific chromosomes and, in most instances, to specific regions of those chromosomes. (More than 50 other disorders are known to be caused by mutations in genes on the $\mathrm{X}$ chromosome but their regional location is not known and therefore they have not been included in this count.) The $\mathbf{9 2 8}$ disorders are distributed over 767 loci; many loci have more than one allelic mutation producing distinct phenotypes.

Recent examples of disorders that have been mapped to specific sites by virtue of mapping of the wild type gene (labelled with the number 1) include Crigler-Najjar syndrome, glycogen storage disease, type I, and metaphyseal chondrodysplasia, Schmid type.

Recent examples of disorders (labelled with the number 2) that have been mapped only on the basis of the clinical phenotype, which is found to be linked to markers at a particular chromosomal site or is found in association with a chromosomal aberration, include alkaptonuria, cartilage-hair hypoplasia, familial dysautonomia, hereditary haemorrhagic telangiectasia, and Werner syndrome. Rubinstein-Taybi syndrome was mapped on the basis of a chromosomal aberration. The mapping information provides the starting point for isolating the mutant gene by positional cloning or the candidate gene approach.

In the case of yet other disorders (labelled with the number 3) the clinical disorder and the wild type gene have been separately mapped. These include instances in which the candidate gene approach has led to definition of the basic defect in the clinical disorder. Examples in the last year included familial amyotrophic lateral sclerosis, type I (wild type gene = SOD1), supravalvar aortic stenosis (wild type gene = elastin), stenosis of the aqueduct of Sylvius (wild type gene = L1CAM), X linked Charcot-Marie-Tooth disease (wild type gene $=$ connexin-32), and $\mathrm{X}$ linked immunodeficiency with hyper-IgM (wild type gene $=$ CD40 ligand) .

Mapping of genetic disorders has shed light on both allelism and non-allelism. Examples of non-allelic genetic heterogeneity found or extended in the last year include the following: the number of distinguished types of CharcotMarie-Tooth disease were increased by the mapping of forms to $1 p$ and $8 q$; in addition to the forms already mapped, two types of familial hypertrophic cardiomyopathy were mapped to chromosomes 15 and 11 ; a third form of spinocerebellar ataxia was located to chromosome 14; non-allelic heterogeneity in multiple exostoses and Wagner syndrome was established by finding linkage in some families to chromosome 8 or 12 , respectively, but not in others. The practice is to assign a number to the various types of a particular disorder as they are defined; for example, CMH1-4 for the forms of hypertrophic cardiomyopathy. The number of forms of retinitis pigmentosa defined on the basis of linkage has now reached RP10. As soon as the nature of the gene that is mutated is identified, one can substitute for the number a designation such as "retinitis pigmentosa, rhodopsin-related" or "retinitis pigmentosa, peripherin-related."

Allelic series as the basis of phenotypic diversity, that is, allelic heterogeneity, is illustrated by pairs or sets of phenotypes such as cystic fibrosis and congenital bilateral absence of vas deferens (caused by mutation in the CFTR gene) and the some seven disorders that have been related to mutations in the type II collagen gene. For the most part, refined delineation of allelic heterogeneity has come not from mapping but rather through detection of point mutations and genotype-phenotype correlations.

Some sets of disorders show both non-allelic genetic heterogeneity and allelic genetic heterogeneity in a symmetrical relationship. The earliest and best known example comes from 
the type I collagen genes: certain forms of osteogenesis imperfecta and of Ehlers-Danlos syndrome result from mutation in either the COL1A1 gene on chromosome 17 or the COL1A2 gene on chromosome 7. A more recently elucidated example is epidermolysis bullosa simplex (EBS) which in any one of the distinct Koebner, Dowling-Meara, or WeberCockayne forms can be caused by mutation in either the keratin-5 gene on chromosome 12 or the keratin-14 gene on chromosome 17 . The heterotrimeric structure of type I collagen constituted by polypeptide chains encoded by the COL1A1 and COL1A2 genes and the close structural-functional association of the $\mathrm{K} 5$ and $\mathrm{K} 14$ genes in the epidermis are the basis.

Mapping information suggest that some syndromes with a combination of manifestations may result from mutation in a complex locus, that is, the particular pattern of components may be determined by the part of the gene affected by the mutation. Von HippelLindau syndrome and multiple endocrine neoplasia type II are possible examples. Tissuespecific alternative splicing of RNA might account for different patterns of involved organs depending on the site of the mutation in the gene. Close linkage of mutant genes, each responsible for a specific component, in general is rejected as the cause of genetic syndromes, in favour of pleiotropism. The bona fide nature of some so-called contiguous gene syndromes is unquestionable, however. In the last year, Williams syndrome was identified as a probable contiguous gene syndrome, with the elastin gene as one of the genes affected.

Somatic cell genetic disease is particularly well illustrated by many forms of neoplasia, both solid tumours and leukaemias, that have been traced to genes located at specific sites. Recent examples include acute myeloid leukaemia resulting from mutation in the pseudoautosomal CSF2RA gene and paroxysmal nocturnal haemoglobinuria resulting from mutation in the X linked PIGA gene. Some congenital malformations also represent somatic cell genetic disorders. The Happle hypothesis holds that some disorders are the result of the mosaic state of mutations which would be lethal if present in the non-mosaic state, even in the heterozygote. The McCuneAlbright syndrome (Albright polyostotic fibrous dysplasia), pseudohypoparathyroidism
(Albright hereditary osteodystrophy), and growth hormone secreting pituitary tumour comprise a remarkable set of genetic diseases illustrating an allelic series. The first, a somatic cell genetic disease, is the result of an activating mutation in the GNAS1 gene occurring in early embryogenesis; the second is a loss of function mutation of the GNAS1 gene, and the third represents an activating somatic mutation occurring in a single cell of the anterior pituitary.

We are indebted to colleagues who have participated in the 11 Hum Gene Mapping Workshops 1973 to 1991 and in the Human Gene Mapping Workshops 1973 to 1991 and in the Japan, as well as to others who have assisted in the collation of Japan, as well as to others who have assisted in the collation of data on the human gene map, and, of course, to all who have been responsible for generating data on the mapping of genetic disorders. The development and maintenance of Mendelian inheritance in man and its online version OMIM were supported in part by the Howard Hughes Medical Institute from 1985 to 1991. It is now supported jointly by the National Center for Human Genome Research of NIH and by the DOE as part of the Genome Data Base (GDB), the repository for mapping information coming from the Human Genome Project.

Editorial note. It is our intention to publish an annual update of this information.

\section{References}

1 McKusick VA Mendelian inheritance in man. 10th ed. Baltimore: The Johns Hopkins University Press, 1992. (This print version of MIM is published each two years. The 11 th edition will be available in mid-1994. Mendelian inheritance in man in updated form is also released each 6 inheritance in man in updated form is also released each 6
months on CD-ROM by Johns Hopkins University Press months on CD-ROM by Johns
and Aries Systems Corporation.)

2 References for the new mapping information and additional information about the loci and disorders are provided in the continuously updated OMIMTM (Online Mendelian inheritance in man). To obtain information on accessing OMIM, contact:

In the United States: GDB/OMIM User Support, Genome Data Base, Johns Hopkins University, 2024 E. Monome Data Base, Johns Hopkins University, 2024 E. Monument Street, Baltimore, MD 21205-2100, USA
(Telephone: 410-955-7058, FAX: 410-614-0434, Internet: help@gdb.org).

In the United Kingdom: Christine Bates, Human Gene In the United Kingdom: Christine Bates, Human Gene
Mapping Program Resource Centre, CRC, Watford Road, Mapping Program Resource Centre, CRC, Watford Road, Harrow MIDDX HA1 3UJ, UK (Telephone: 44-81-869In Germany: Otto Ritter, German Cancer Research Centre (DKFZ), Molecular Biophysics Dept., Im Neuenheimer Feld 280, D-6900 Heidelberg 1, FRG (Telephone: 49-6221-42-2372, FAX: 49-6221-42-2333, Internet: dok261@cvx12.dkfz-heidelberg.de).

In Australia: Alex Reisner, ANGIS, Electrical Engineering Bldg. J03, University of Sydney, Sydney, NSW 2006, Australia (Telephone: 61-2-692-2948, FAX: 61-2-692-3847, Internet: reisner@angis.su.oz.au). In The Netherlands: GDB User Support, CAOS/CAMM Center, Faculty of Science, University of Nijmegen, PO Box 9010, 6500 GL Nijmegen, Netherlands (Telephone: 31-80-653-391, FAX: 31-65277, Internet: post@caos.caos.kun.nl).

In Sweden: GDB User Support, Biomedical Center, Box 570, S-751 23 Uppsala, Sweden (Telephone: 46-18174-057, FAX: 46-18-524-869, Internet: help@gdb.embnet.se). 

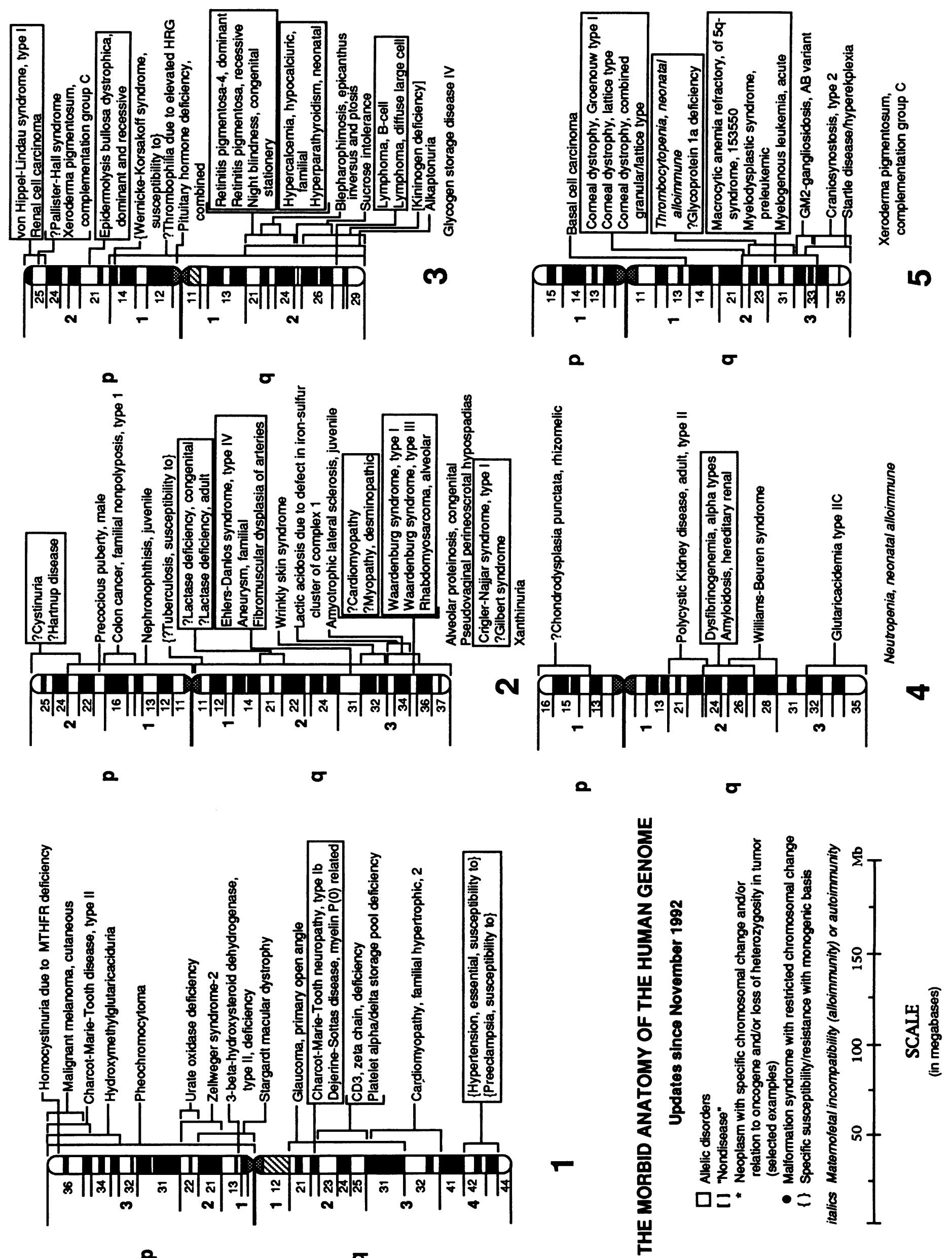

The morbid anatomy of the human genome: New information acquired in the last year is presented. Disorders with confirmed or provisional assignments have been included. Because of the large number of disorders assigned to specific regions of the $X$ chromosome, only selected ones are represented here. 


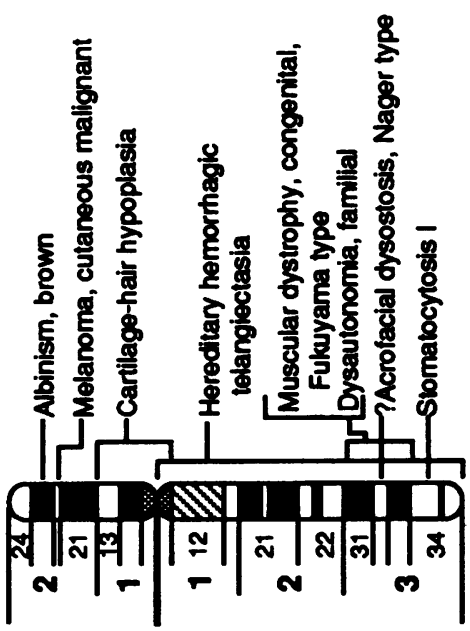

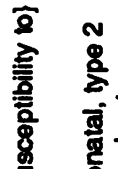

a

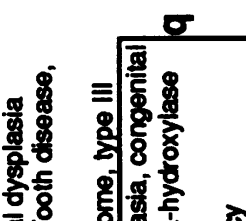

क

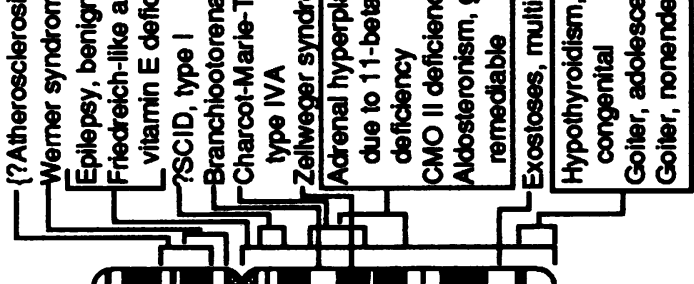

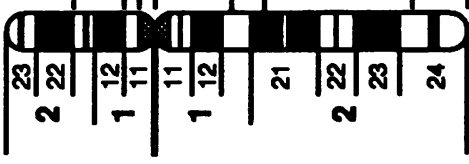

a

$\sigma$

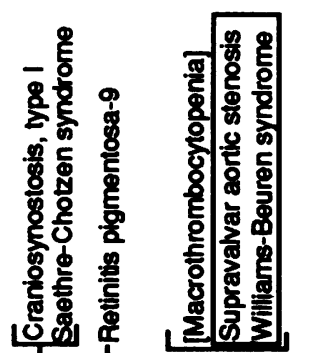

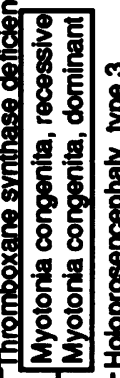

$\infty$
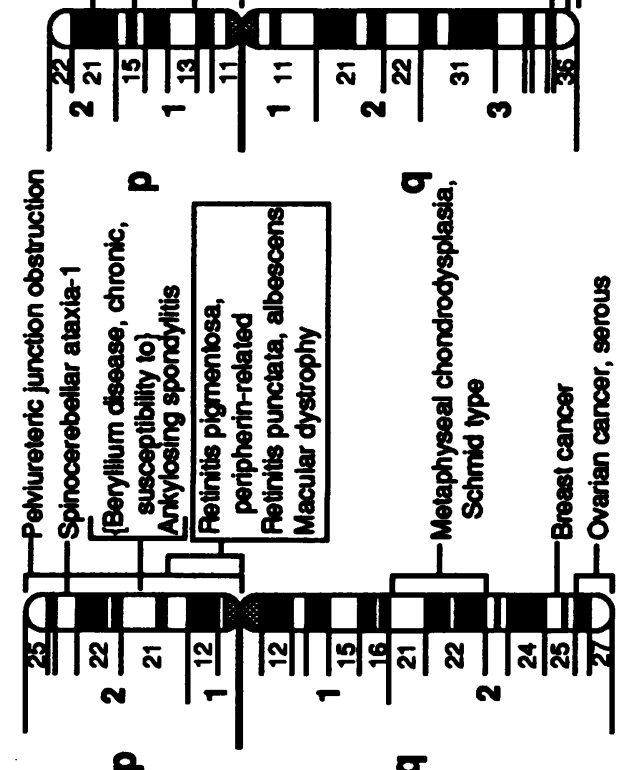

$\infty$
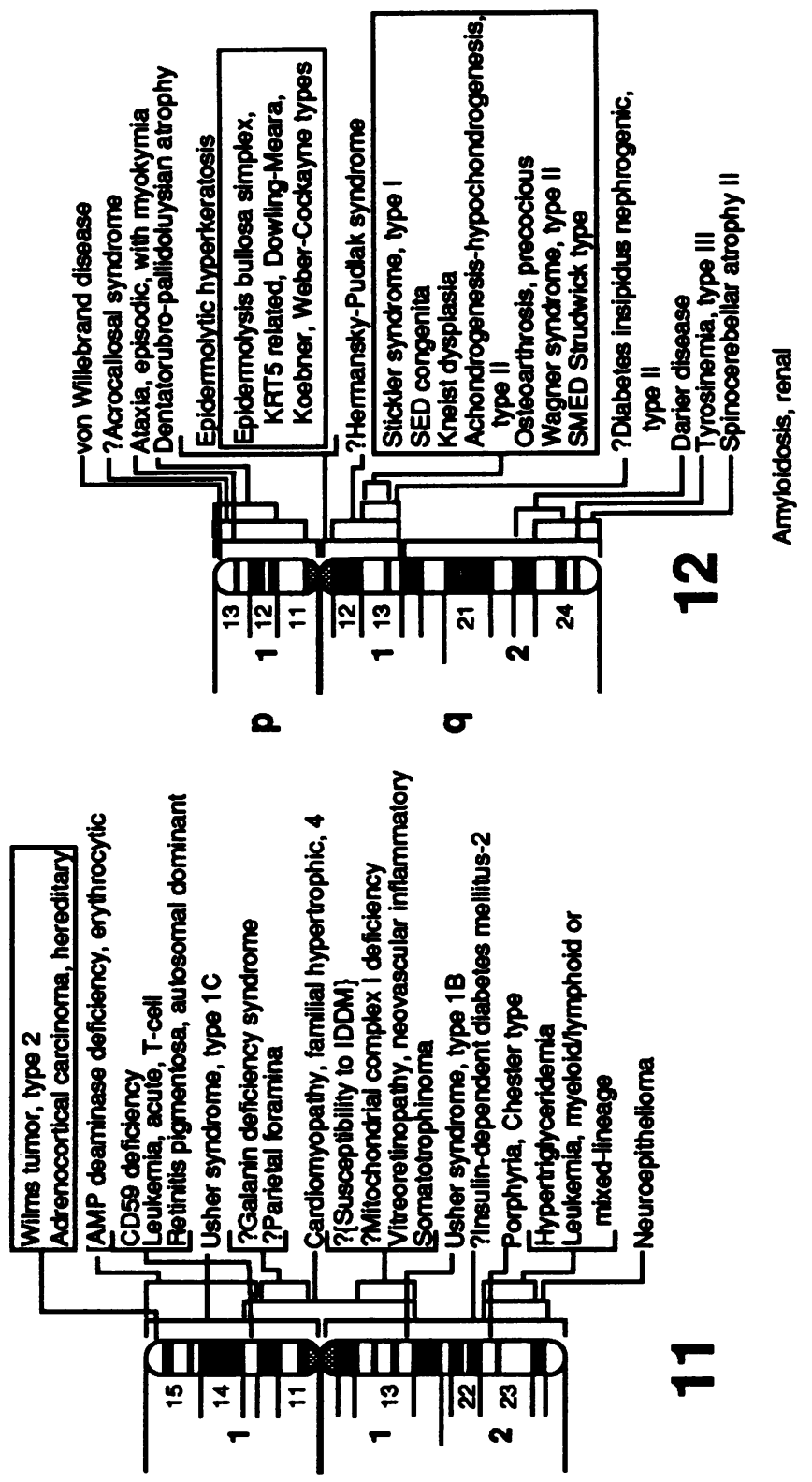

a

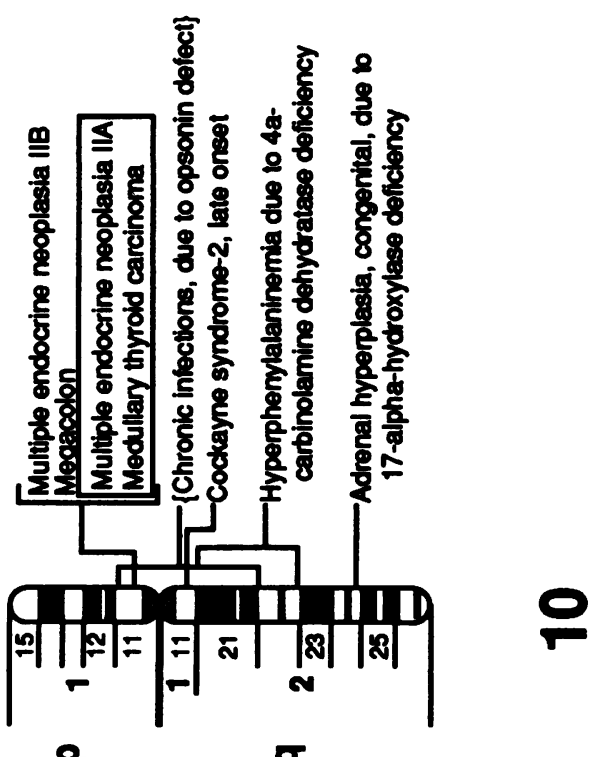



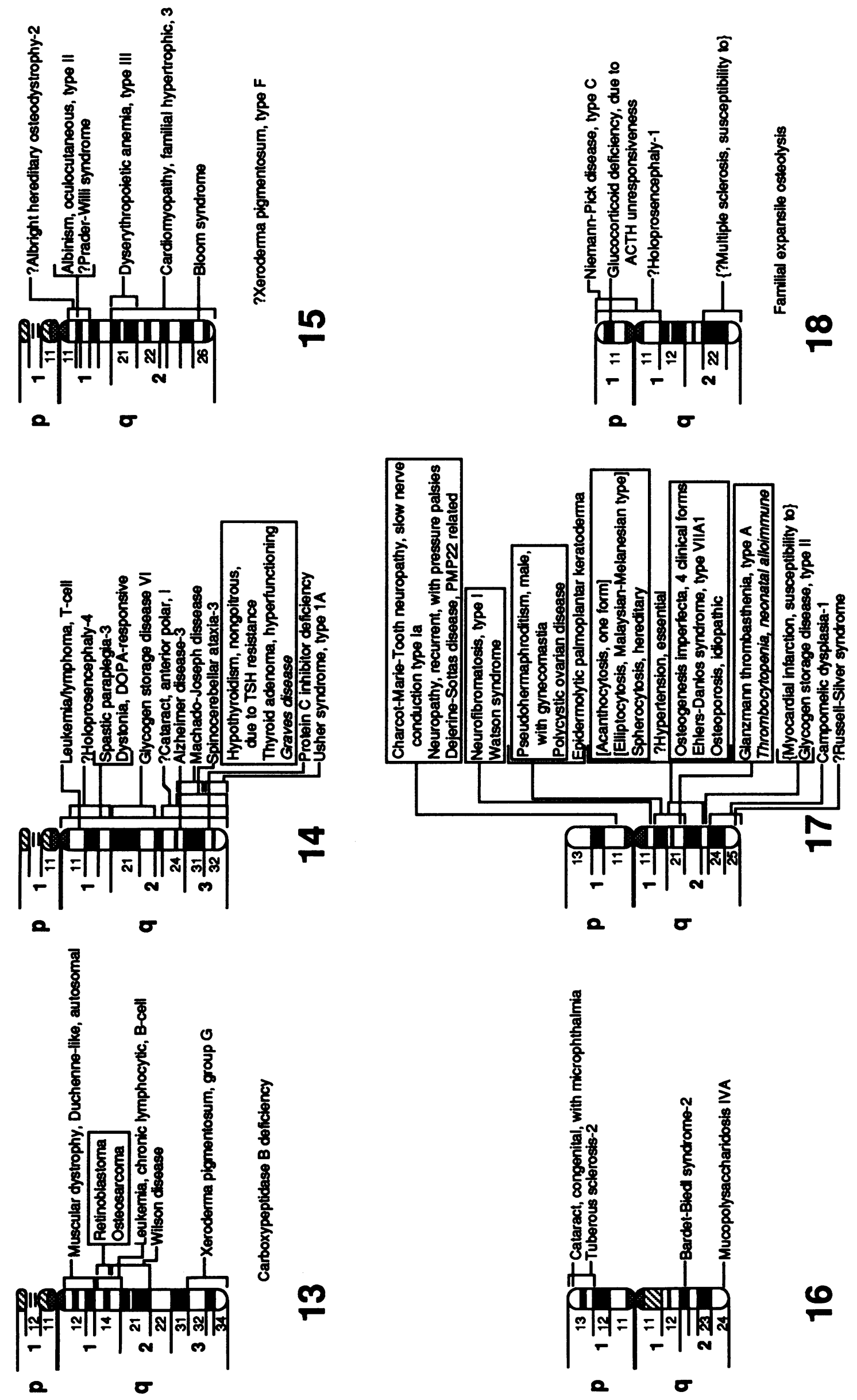

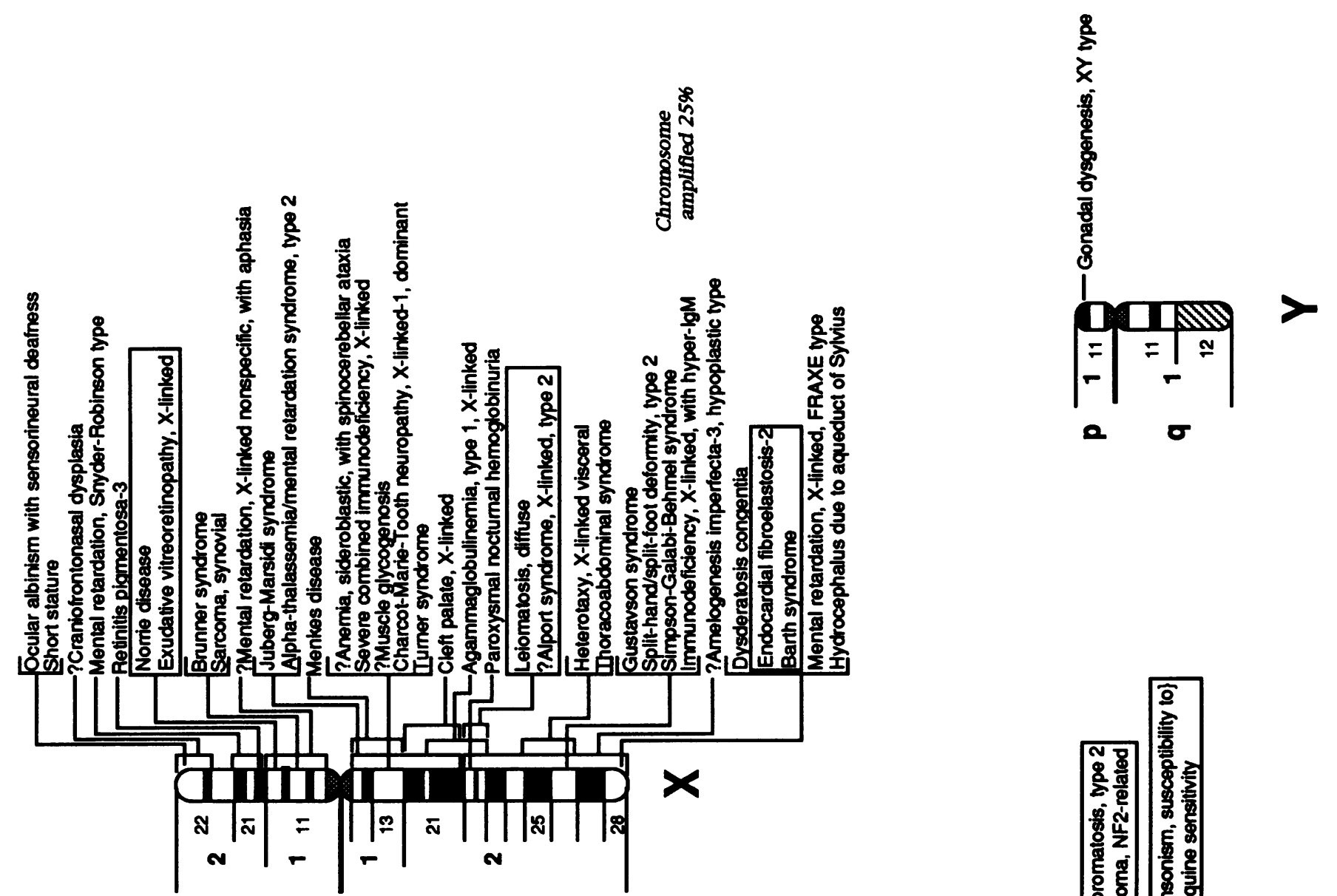

a
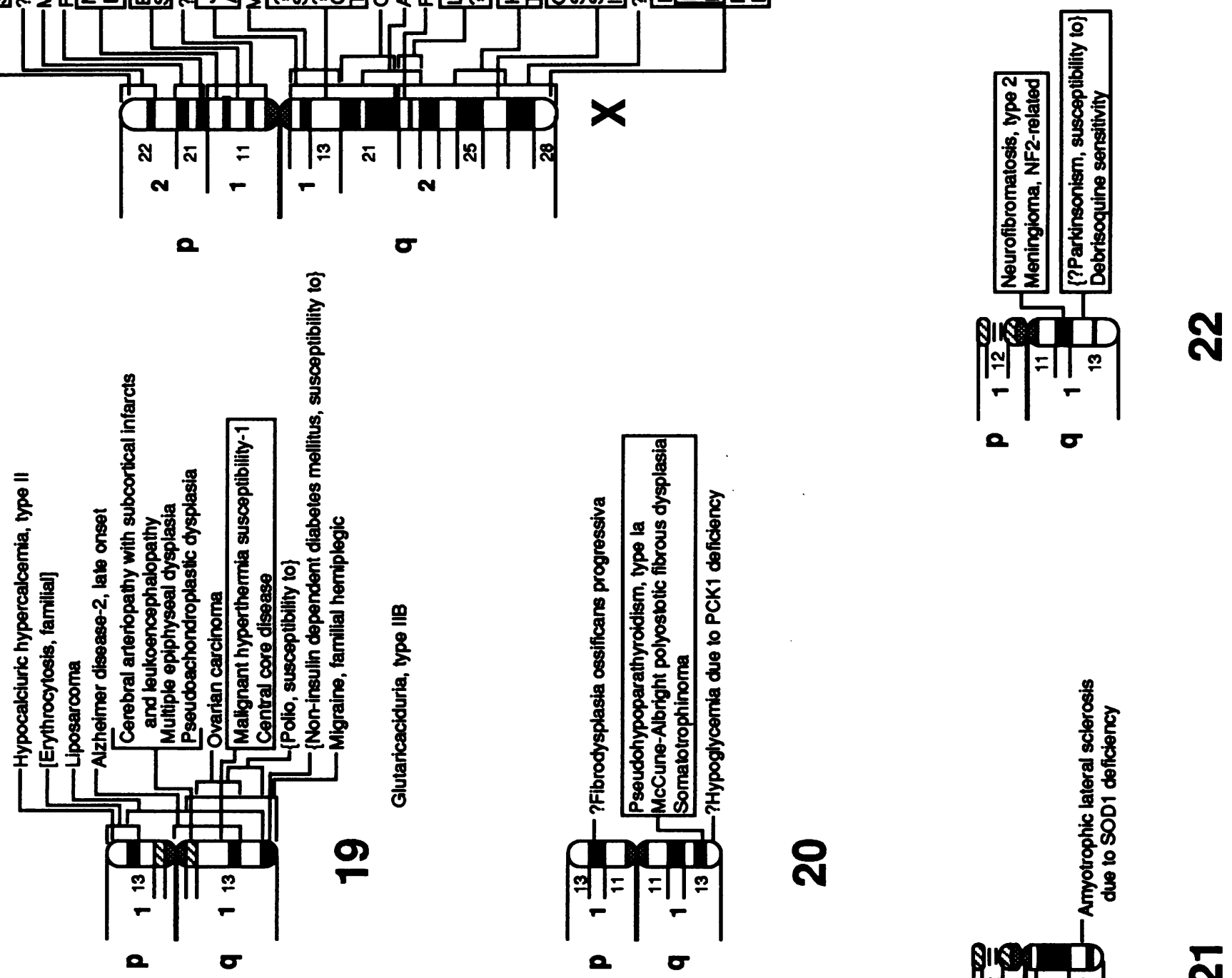

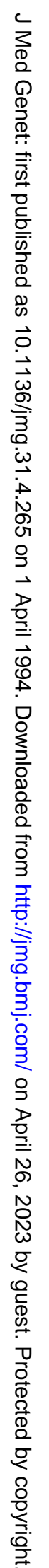


Table 1 The morbid anatomy of the human genome (by chromosome)

\begin{tabular}{|c|c|c|c|c|c|c|c|}
\hline Location & Symbol & Stat & Title & MIM \# & Method & Disorder & Mouse \\
\hline 1pter-p33 & HMGCL & $\mathbf{P}$ & $\begin{array}{l}\text { 3-hydroxy-3-methylglutaryl } \\
\text { CoA lyase }\end{array}$ & 246450 & $\mathrm{REa}, \mathrm{A}$ & Hydroxymethylglutaricaciduria (1) & \\
\hline $1 \mathrm{p} 36.3$ & MTHFR & $\mathbf{P}$ & $\begin{array}{l}\text { Methylenetetrahydrofolate } \\
\text { reductase }\end{array}$ & 236250 & A & $\begin{array}{l}\text { Homocystinuria due to MTHFR } \\
\text { deficiency (3) }\end{array}$ & \\
\hline $1 \mathrm{p} 36$ & $\begin{array}{l}\text { CMM, HCMM, } \\
\text { MLM, DNS }\end{array}$ & $\mathbf{P}$ & $\begin{array}{l}\text { Cutaneous malignant melanoma/ } \\
\text { dysplastic nevus }\end{array}$ & 155600 & F, Fd, D & Malignant melanoma, cutaneous (2) & \\
\hline 1p36-p35 & CMT2 & $\mathbf{P}$ & $\begin{array}{l}\text { Charcot-Marie-Tooth neuropathy-2 } \\
\text { (hereditary motor sensory } \\
\text { neuropathy II) }\end{array}$ & 118210 & Fd & $\begin{array}{l}\text { Charcot-Marie-Tooth disease, } \\
\text { type II (2) }\end{array}$ & \\
\hline $1 \mathrm{p} 22$ & UOX & $\mathbf{P}$ & Urate oxidase & 191540 & REa, A & Urate oxidase deficiency (1) & \\
\hline 1p22-p21 & PXMP1, PMP70 & $\mathbf{P}$ & $\begin{array}{l}\text { Peroxisomal membrane } \\
\text { protein-1 }(70 \mathrm{kD})\end{array}$ & 170995 & REa, A & Zellweger syndrome-2 (1) & 3(Pmp70) \\
\hline $1 \mathrm{p} 13.1$ & HSD3B2 & C & $\begin{array}{l}\text { Hydroxy-delta-5-steroid steroid } \\
\text { delta-isomerase, type } 2 \text { (adrenal, } \\
\text { gonadal) }\end{array}$ & 201810 & A & $\begin{array}{l}\text { 3-beta-hydroxysteroid deficiency (3) } \\
\text { dehydrogenase, type II }\end{array}$ & $3(\mathrm{Hsd} 3 \mathrm{~b} 2)$ \\
\hline lp & PCHC & $\mathbf{P}$ & Pheochromocytoma & 171300 & D & Pheochromocytoma (2) & \\
\hline 1p21-p13 & STGD & $\mathbf{P}$ & Stargardt macular dystrophy & 248200 & Fd & Stargardt macular dystrophy (2) & \\
\hline $1 q 21-q 31$ & POAG, GPOA & $\mathbf{P}$ & Glaucoma, primary open angle & 137760 & Fd & $\begin{array}{l}\text { Glaucoma, primary open angle, } \\
\text { juvenile-onset (2) }\end{array}$ & \\
\hline $1 \mathrm{q} 22$ & $\begin{array}{l}\text { MPZ, MPP, } \\
\text { CMT1B }\end{array}$ & C & Myelin protein zero & 159440 & $\begin{array}{l}\text { REb, A, F, } \\
\quad \text { Fd, D }\end{array}$ & $\begin{array}{l}\text { Charcot-Marie-Tooth neuropathy, } \\
118200(3) ; \text {, slow nerve } \\
\text { conduction type Ib, Dejerine- } \\
\text { Sottas disease, myelin } \mathrm{P}(0) \\
\text {-related, } 145900(3)\end{array}$ & $1(\mathrm{Mpp})$ \\
\hline 1q23-q21.1 & CD3Z, TCRZ & C & $\begin{array}{l}\text { Antigen CD3Z, zeta polypeptide } \\
\text { (TiT3 complex) }\end{array}$ & 186780 & REa, A, REn & CD3, zeta chain, deficiency (1) & $1(T 3 z, C d 3 z)$ \\
\hline $1 q 23-q 25$ & SELP, GRMP & C & $\begin{array}{r}\text { Selectin P (granulocyte membrane } \\
\text { protein, 140kD; antigen CD62) }\end{array}$ & 173610 & REn, A & $\begin{array}{l}\text { Platelet alpha/delta storage pool } \\
\text { deficiency (1) }\end{array}$ & 1 (Grmp) \\
\hline $1 \mathrm{q} 3$ & CMH2 & $\mathbf{P}$ & $\begin{array}{l}\text { Cardiomyopathy, familial } \\
\text { hypertrophic, } 2\end{array}$ & 115195 & Fd & $\begin{array}{l}\text { Cardiomyopathy, familial } \\
\text { hypertrophic, } 2(2)\end{array}$ & \\
\hline $1 q 42-q 43$ & AGT & C & Angiotensinogen & 106150 & A, REa & $\begin{array}{l}\text { \{Hypertension, essential, } \\
\text { susceptibility to\} (3); } \\
\text { \{Preeclampsia, susceptibility } \\
\text { to\} (3) }\end{array}$ & 8(Agt) \\
\hline 2pter-q32.3 & ATR1, D2H & $\mathbf{P}$ & Amino acid-transporter-1 & 104614 & REa & $\begin{array}{l}\text { ?Cystinuria, } 220100(1) \text {; ?Hartnup } \\
\text { disease, } 234500(1)\end{array}$ & \\
\hline 2p23-cen & NPH1 & $\mathbf{P}$ & Nephronophthisis-1 (juvenile) & 256100 & Fd & Nephronophthisis, juvenile (2) & \\
\hline $2 \mathrm{p} 21$ & LHCGR & $\mathbf{P}$ & $\begin{array}{l}\text { Luteinizing hormone/ } \\
\text { choriogonadotropin receptor }\end{array}$ & 152790 & A & Precocious puberty, male, 176410 (1) & \\
\hline 2p16-p15 & $\begin{array}{l}\text { COCA1, FCC1, } \\
\text { MSH }\end{array}$ & $\mathbf{P}$ & $\begin{array}{l}\text { Colon cancer, familial, } \\
\text { nonpolyposis type } 1\end{array}$ & 120435 & Fd & $\begin{array}{l}\text { Colon cancer, familial, nonpolyposis } \\
\text { type } 1 \text { (3) }\end{array}$ & \\
\hline $2 q$ & TBS, BCG & $\mathbf{L}$ & $\begin{array}{l}\text { Mycobacterial infections, } \\
\text { susceptibility to }\end{array}$ & 209950 & $\mathrm{H}, \mathrm{Fd}$ & $\{?$ Tuberculosis, susceptibility to\} (2) & \\
\hline $2 \mathrm{q} 21$ & LCT, LAC, LPH & C & Lactase & 223000 & $\begin{array}{l}\text { REa, Fd, A, } \\
\text { Psh }\end{array}$ & $\begin{array}{l}\text { ?Lactase deficiency, congenital (1); } \\
\text { ?Lactase deficiency, adult, } 223100 \text { (1) }\end{array}$ & \\
\hline $2 q 31$ & COL3A1 & C & $\begin{array}{l}\text { Collagen, type III, alpha-1 } \\
\text { polypeptide }\end{array}$ & 120180 & $\mathrm{REa}, \mathrm{A}$ & $\begin{array}{l}\text { Ehlers-Danlos syndrome, type IV, } \\
130050 \text { (3); Aneurysm, familial, } \\
100070 \text { (1); Fibromuscular } \\
\text { dysplasia of arteries, } 135580 \text { (1) }\end{array}$ & $1($ Col3a-1) \\
\hline $2 q 32$ & WSS & $\mathbf{P}$ & Wrinkly skin syndrome & 278250 & $\mathrm{Ch}$ & Wrinkly skin syndrome (2) & \\
\hline $2 q 33-q 34$ & NDUFS1 & $\mathbf{P}$ & $\begin{array}{l}\text { NADH dehydrogenase } \\
\text { ubiquinone), Fe-S protein-1 } \\
\text { (75kD) }\end{array}$ & 157655 & A & $\begin{array}{l}\text { Lactic acidosis due to defect in } \\
\text { iron-sulfur cluster of complex I (1) }\end{array}$ & \\
\hline 2q33-q35 & ALS2, ALSJ & $\mathbf{P}$ & $\begin{array}{l}\text { Amyotrophic lateral sclerosis-2 } \\
\text { (juvenile) }\end{array}$ & 205100 & Fd & $\begin{array}{l}\text { Amyotrophic lateral sclerosis, } \\
\text { juvenile (2) }\end{array}$ & \\
\hline $2 \mathrm{q} 35$ & DES & $\mathbf{P}$ & Desmin & 125660 & REa, A & $\begin{array}{l}\text { ?Cardiomyopathy (1); ?Myopathy, } \\
\text { desminopathic (1) }\end{array}$ & 1(Des) \\
\hline $2 q 35$ & $\begin{array}{l}\text { PAX3, WS1, } \\
\text { HUP2 }\end{array}$ & C & Paired box homeotic gene- 3 & 193500 & $\mathrm{Ch}, \mathrm{Fd}, \mathrm{H}, \mathrm{A}$ & $\begin{array}{l}\text { Waardenburg syndrome, type I (3); } \\
\text { Waardenburg syndrome, type III, } \\
148820 \text { (3); Rhabdomyosarcoma, } \\
148820 \text { (3); Rhabdomyosarcoma, } \\
\text { 1(Sp) }\end{array}$ & \\
\hline Chr.2 & SFTP3 & C & $\begin{array}{l}\text { Pulmonary surfactant- } \\
\text { associated protein-3, 18kD }\end{array}$ & 178640 & REa & $\begin{array}{l}\text { Alveolar proteinosis, } \\
\text { congenital, } 265120 \text { (1) }\end{array}$ & $6($ Sftp-3) \\
\hline Chr.2 & SRD5A2 & $\mathbf{P}$ & $\begin{array}{l}\text { Steroid-5-alpha-reductase, alpha } \\
\text { polypeptide-2 (3-oxo-5 } \\
\text { alpha-steroid delta } \\
\text { 4-dehydrogenase alpha-2) }\end{array}$ & 264600 & REa & $\begin{array}{l}\text { Pseudovaginal perineoscrotal } \\
\text { hypospadias (1) }\end{array}$ & \\
\hline Chr.2 & $\begin{array}{l}\text { UGT1A1, UGT1, } \\
\text { GNT1 }\end{array}$ & $\mathbf{P}$ & $\begin{array}{l}\text { UDP-glucuronosyltransferase-1 } \\
\text { family, member } 1\end{array}$ & 191740 & REa & $\begin{array}{l}\text { Crigler-Najjar syndrome, type I, } \\
218800 \text { (1); } \\
\text { ?Gilbert syndrome, } 143500 \text { (1) }\end{array}$ & 1 (Ugt-1) \\
\hline Chr.2 & $\mathrm{XDH}$ & $\mathbf{P}$ & $\begin{array}{l}\text { Xanthine dehydrogenase } \\
\text { (xanthine oxidase) }\end{array}$ & 278300 & $\mathbf{R E b}$ & Xanthinuria (1) & \\
\hline $3 p 26-p 25$ & VHL & C & von Hippel-Lindau syndrome & 193300 & Fd, D, RE & $\begin{array}{l}\text { von Hippel-Lindau syndrome (3); } \\
\text { Renal cell carcinoma (1) }\end{array}$ & \\
\hline $3 p 25.3$ & PHS & L & Pallister-Hall syndrome & 146510 & $\mathrm{Ch}$ & ?Pallister-Hall syndrome (2) & \\
\hline $3 p 25$ & XPC, XPCC & $\mathbf{P}$ & $\begin{array}{l}\text { Xeroderma pigmentosum, } \\
\text { complementation group C }\end{array}$ & 278720 & REa, A & $\begin{array}{l}\text { Xeroderma pigmentosum, } \\
\text { complementation group C (2) }\end{array}$ & \\
\hline $3 \mathrm{p} 21.3$ & COL7A1 & C & Collagen VII, alpha-1 polypeptide & 120120 & REa, A & $\begin{array}{l}\text { Epidermolysis bullosa dystrophica, } \\
\text { dominant, } 131750(3) \\
\text { Epidermolysis bullosa } \\
\text { dystrophica, recessive, } 226600 \text { (3) }\end{array}$ & \\
\hline $3 \mathrm{p} 14.3$ & TKT & $\mathbf{P}$ & Transketolase & 277730 & $\mathrm{REa}, \mathrm{A}$ & $\begin{array}{l}\text { \{Wernicke-Korsakoff syndrome, } \\
\text { susceptibility to\} (1) }\end{array}$ & \\
\hline 3p14-qter & HRG & $\mathbf{P}$ & Histidine-rich glycoprotein & 142640 & REa & $\begin{array}{l}\text { ?Thrombophilia due to elevated } \\
\text { HRG (1) }\end{array}$ & \\
\hline $3 p 11$ & PIT1 & C & $\begin{array}{l}\text { Pituitary-specific transcription } \\
\text { factor Pit-1 }\end{array}$ & 173110 & Fd, A & $\begin{array}{l}\text { Pituitary hormone deficiency, } \\
\text { combined (1) }\end{array}$ & 16(Pit-1,dw) \\
\hline
\end{tabular}


Table 1 - contd

\begin{tabular}{|c|c|c|c|}
\hline Location & Symbol & Status & Title \\
\hline $\begin{array}{l}3 q 2 \\
3 q 21-q 24\end{array}$ & $\begin{array}{l}\text { AKU } \\
\text { HHC1, FHH, } \\
\text { PCAR1 }\end{array}$ & $\begin{array}{l}\mathbf{C} \\
\mathbf{P}\end{array}$ & $\begin{array}{l}\text { Alkaptonuria } \\
\text { Hypocalciuric hypercalcemia-1 } \\
\text { (parathyroid } \mathrm{Ca}(2+)- \\
\text { sensing receptor) }\end{array}$ \\
\hline $3 q 21-q 24$ & RHO, RP4 & C & Rhodopsin \\
\hline
\end{tabular}

MIM \#

Disorder

Mouse

203500

Fd, $\mathrm{H} \quad$ Alkaptonuria (2)

16(aku)

Fd, REa Hypercalcemia, hypocalciuric, familial (3); Hyperparathyroidism, neonatal 239200 (3)

80380 REa, A, Fd Retinitis pigmentosa-4,

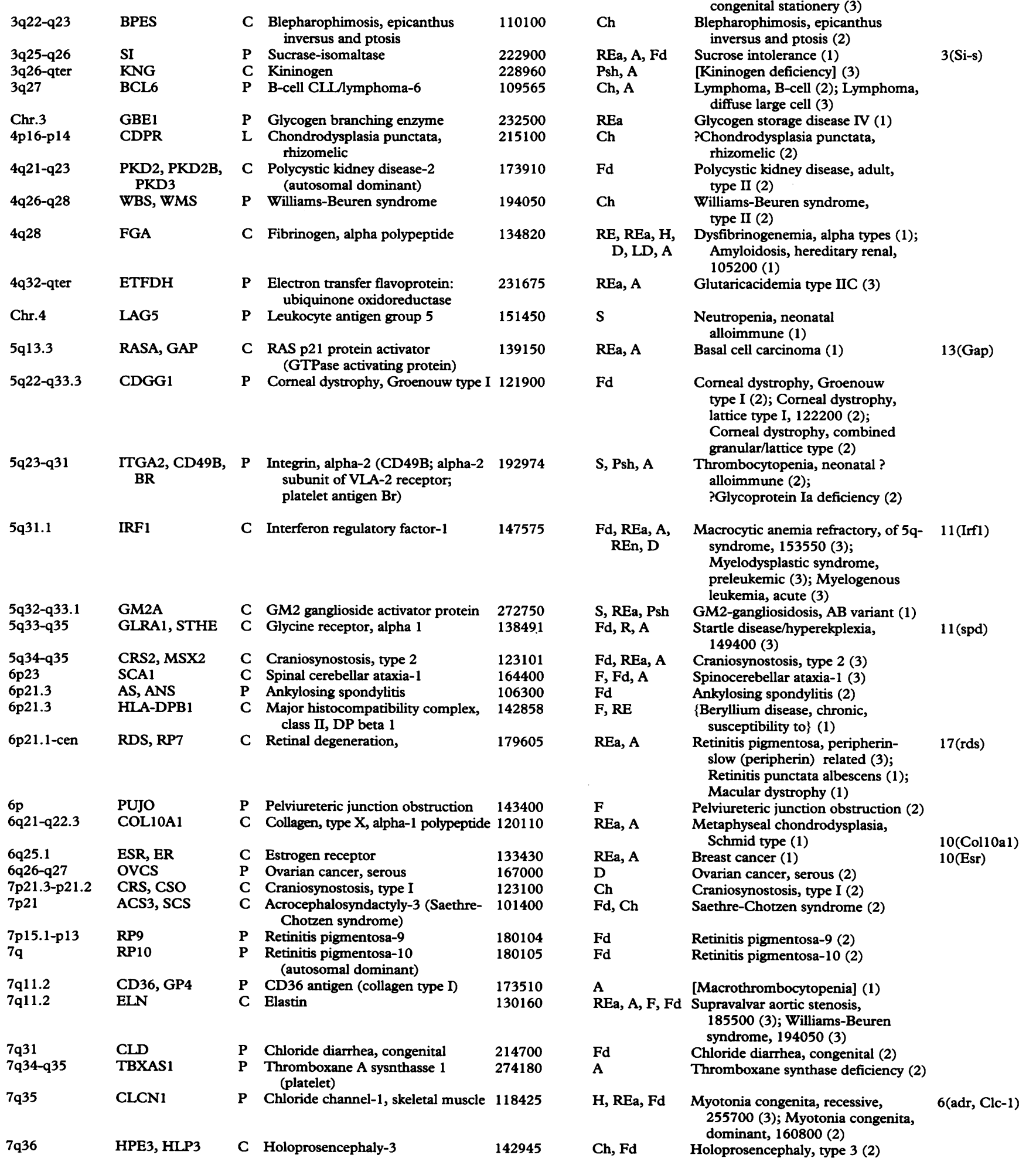

8p21-p12 CLU, CLI, SGP2, C Clusterin (complement lysis

185430 inhibitor, SP-40,40; sulfated glycoprotein 2; testosteronerepressed prostate message-2; apolipoprotein $\mathrm{J}$

8p12-p11 WRN C Werner syndrome autosomal dominant (3); Retinitis pigmentosa, autosomal recessive (3); Night blindness, congenital stationery (3)

REa, REb, A, \{?Atherosclerosis, susceptibility

6(Rho) 
Table 1 - contd

\begin{tabular}{|c|c|c|c|c|c|c|c|}
\hline Location & Symbol & Stat & Title & $M I M \#$ & Method & Disorder & Mouse \\
\hline $8 q$ & EBN2 & $\mathbf{P}$ & $\begin{array}{l}\text { Epilepsy, benign neonatal-2 (benign } 1 \\
\text { familial neonatal convulsions) }\end{array}$ & 121201 & Fd & Epilepsy, benign neonatal, type 2 (2) & \\
\hline $8 q$ & AVED & $\mathbf{P}$ & $\begin{array}{l}\text { Ataxia (Friedreich-like) with } \\
\text { selective E deficiency }\end{array}$ & 277460 & Fd, LD & $\begin{array}{l}\text { Friedreich-like ataxia, due to } \\
\text { vitamin E deficiency (2) }\end{array}$ & \\
\hline $8 q 11$ & HYRC1 & $\mathbf{P}$ & $\begin{array}{l}\text { Hyperradiosensitivity of murine } \\
\text { SCID mutation, complementing-1 }\end{array}$ & 202500 & C & $\begin{array}{l}\text { ?Severe combined immunodeficiency, } \\
\text { type I (1) }\end{array}$ & 16 (scid) \\
\hline $8 \mathrm{q} 13-\mathrm{q} 21.1$ & CMT4A, CMT4 & $\mathbf{P}$ & $\begin{array}{l}\text { Charcot-Marie-Tooth } \\
\text { neuropathy-4A (autosomal recessive } \\
\text { recessive) }\end{array}$ & $\begin{array}{l}214400 \\
\text { ve) }\end{array}$ & Fd & $\begin{array}{l}\text { Charcot-Marie-Tooth disease, type } \\
\text { IVA (2) }\end{array}$ & \\
\hline $8 q 13.3$ & BOR, BOS & C & Branchiootorenal syndrome & 113650 & $\mathrm{Ch}, \mathrm{Fd}$ & Branchiootorenal dysplasia (2) & \\
\hline $8 \mathrm{q} 21$ & $\begin{array}{l}\text { CYP11B1, } \\
\text { P450C11 }\end{array}$ & C & $\begin{array}{l}\text { Cytochrome P450, subfamily XIB, } \\
\text { polypeptide-1; 11-beta-hydroxylase; } \\
\text { corticosteroid methyl-oxidase II } \\
\text { (CMO II) }\end{array}$ & 202010 & $\mathrm{REa}, \mathrm{A}, \mathrm{Ch}$ & $\begin{array}{l}\text { Adrenal hyperplasia, congenital, due } \\
\text { to } 11 \text {-beta-hydroxylase deficiency (1) } \\
\text { CMO II deficiency (1); } \\
\text { Aldosteronism, glucocorticoid- } \\
\text { remediable (1) }\end{array}$ & \\
\hline $8 q 21.1$ & PAF1, PMP35 & C & Peroxisomal assembly factor-1 $(35 \mathrm{kD}) 1$ & 170993 & RE & Zellweger syndrome-3 (3) & \\
\hline $8 \mathrm{q} 24.11-\mathrm{q} 24.13$ & EXT1, EXT & $\mathbf{P}$ & Exostoses (multiple) 1 & 133700 & $\mathrm{Ch}, \mathrm{Fd}$ & Exostoses, multiple, type 1 (2) & \\
\hline $8 \mathrm{q} 24.2-\mathrm{q} 24.3$ & TG & C & Thyroglobulin & 188450 & $A, R E a, R E b$ & $\begin{array}{l}\text { Hypothyroidism, hereditary } \\
\text { congenital (1); Goiter, adolescent } \\
\text { multinodular (1); Goiter, } \\
\text { nonendemic, simple (1) }\end{array}$ & 15(Tgn; cog) \\
\hline 9p23 & $\begin{array}{l}\text { TYRP, CAS2, } \\
\text { CATB }\end{array}$ & C & $\begin{array}{l}\text { Tyrosinase-related protein (catalase } 1 \\
\text { B; human homolog of } \\
\text { 'brown' locus) }\end{array}$ & 115501 & Psh, REa, A & Albinism, brown, 203290 (1) & 4(b;trp-1) \\
\hline $9 \mathrm{p} 21$ & $\begin{array}{l}\text { MLM, CMM2, } \\
\text { MLM2 }\end{array}$ & C & Melanoma & 155601 & $\mathrm{D}, \mathrm{Fd}$ & Melanoma, cutaneous malignant (2) & \\
\hline 9p13-q11 & $\mathrm{CHH}$ & $\mathbf{P}$ & Cartilage-hair hypoplasia & 250250 & Fd & Cartilage-hair hypoplasia (2) & \\
\hline $9 q$ & ORW, HHT & $\mathbf{P}$ & $\begin{array}{l}\text { Osler-Rendu-Weber syndrome ) } \\
\text { (hereditary hemorrhagic } \\
\text { telangiectasia) }\end{array}$ & 187300 & $\mathrm{Fd}$ & $\begin{array}{l}\text { Hereditary hemorrhagic } \\
\text { telangiectasia (2) }\end{array}$ & \\
\hline $9 q 31-q 33$ & DYS & $\mathbf{P}$ & $\begin{array}{l}\text { Dysautonomia (Riley-Day syndrome, } \\
\text { hereditary sensory autonomia } \\
\text { neuropathy type III) }\end{array}$ & 223900 & Fd, LD & Dysautonomia, familial (2) & \\
\hline $9 q 31-q 33$ & FCMD & $\mathbf{P}$ & $\begin{array}{l}\text { Fukuyama type congenital muscular } 2 \\
\text { dystrophy }\end{array}$ & 253800 & Fd, LD & $\begin{array}{l}\text { Fukuyama type congenital muscular } \\
\text { dystrophy (2) }\end{array}$ & \\
\hline 9q32 & AFDN & L & Acrofacial dysostosis, Nager type & 154400 & $\mathrm{Ch}$ & ?Acrofacial dysostosis, Nager type (2) & \\
\hline $9 \mathrm{q} 34.1$ & EPB72 & C & $\begin{array}{l}\text { Erythrocyte membrand protein band } 1 \\
7.2 \text { (stomatin) }\end{array}$ & 185000 & $\mathrm{REa}, \mathrm{Ch}, \mathrm{A}$ & Stomatocytosis I (2) & \\
\hline $10 \mathrm{q} 11.5$ & MEN2B, MEN3 & C & Multiple endocrine neoplasia, type IIB 1 & 162300 & Fd & Multiple endocrine neoplasia IIB (2) & \\
\hline $10 \mathrm{q} 11.2$ & HSCR, MGC & C & Hirschsprung disease & 142623 & $\mathrm{Ch}, \mathrm{Fd}, \mathrm{D}$ & Megacolon (2) & ?14(ls) \\
\hline $10 \mathrm{q} 11.2$ & RET, MEN2A & C & $\begin{array}{l}\text { RET transforming sequence; } \\
\text { oncogene RET }\end{array}$ & 164761 & A, REn, Fd & $\begin{array}{l}\text { Multiple endocrine neoplasia IIA, } \\
171400 \text { (3); Medullary thyroid } \\
\text { carcinoma (3) }\end{array}$ & \\
\hline $10 \mathrm{q} 11.2-\mathrm{q} 21$ & MBL, MBP1 & C & Mannose-binding lectin & 154545 & $\mathrm{REa}, \mathrm{A}, \mathrm{Fd}$ & $\begin{array}{l}\text { \{Chronic infections, due to } \\
\text { opsonin defect\} (1) }\end{array}$ & \\
\hline $10 \mathrm{q} 11$ & ERCC6, CKN2 & $\mathbf{P}$ & $\begin{array}{l}\text { Excision repair cross } \\
\text { complementing rodent repair } \\
\text { deficiency, complementation } \\
\text { group } 6\end{array}$ & 133540 & A & $\begin{array}{l}\text { Cockayne syndrome-2, late onset, } \\
216410 \text { (2) }\end{array}$ & \\
\hline $10 \mathrm{q} 21-\mathrm{q} 22$ & $\mathrm{DCOH}, \mathrm{CADH}$ & $\mathbf{P}$ & $\begin{array}{l}\text { Dimerization cofactor of hepatic } \\
\text { nuclear factor 1-alpha (TCF1) } \\
\text { (4a-carbinolamine dehydratase) }\end{array}$ & 126090 & $\mathrm{REa}, \mathrm{H}$ & $\begin{array}{l}\text { Hyperphenylalaninemia due to } \\
\text { 4a-carbinolamine dehydratase } \\
\text { deficiency, } 264070 \text { (1) }\end{array}$ & 10 (Dcoh) \\
\hline $10 \mathrm{q} 24.3$ & CYP17, P450C17 & C & $\begin{array}{l}\text { Cytochrome P450, subfamily XVII; } 2 \\
\text { steroid 17-alpha-hydroxylase }\end{array}$ & 202110 & $\mathrm{REa}, \mathrm{H}, \mathrm{A}$ & $\begin{array}{l}\text { Adrenal hyperplasia, congenital, due } \\
\text { to } 17 \text {-alpha-hydroxylase } \\
\text { deficiency (1) }\end{array}$ & 19(Cyp17) \\
\hline 11 pter-p13 & AMPD3 & $\mathbf{P}$ & $\begin{array}{l}\text { Adenosine monophosphate } \\
\text { deaminase } 3 \text { (isoform E) }\end{array}$ & 102772 & REa & $\begin{array}{l}\text { [AMP deaminase deficiency, } \\
\text { erythrocytic] (1) }\end{array}$ & \\
\hline $11 \mathrm{p} 15.5$ & MTACR1, WT2 & $\mathbf{P}$ & $\begin{array}{l}\text { Multiple tumor associated } \\
\text { chromosome region-1 }\end{array}$ & 194071 & D & $\begin{array}{l}\text { Wilms tumor, type } 2(2) \text {; } \\
\text { Adrenocortical carcinoma, } \\
\text { hereditary (2) }\end{array}$ & \\
\hline $11 \mathrm{p} 13$ & CD59 & C & Antigen CD59 (p18-20) & 107271 & REa, A, D & CD59 deficiency (3) & 15(Ly-6) \\
\hline $11 \mathrm{p} 13$ & $\begin{array}{l}\text { RBTNL1, } \\
\text { RBTN2, RHOM2, } \\
\text { TTG2 }\end{array}$ & $\mathbf{P}$ & Rhombotin-like 1 & 180385 & $\mathrm{REa}, \mathrm{REc}$ & Leukemia, acute, T-cell (2) & \\
\hline $11 \mathrm{p} 13$ & ROM1, ROSP1 & $\mathbf{P}$ & $\begin{array}{l}\text { Rod outer segment membrane } \\
\text { protein-1 }\end{array}$ & 180721 & REa & $\begin{array}{l}\text { Retinitis pigmentosa, autosomal } \\
\text { dominant (1) }\end{array}$ & 19(Rosp-1) \\
\hline $11 \mathrm{p} 13-\mathrm{q} 13$ & CMH4 & $\mathbf{P}$ & $\begin{array}{l}\text { Cardiomyopathy, familial } \\
\text { hypertrophic, } 4\end{array}$ & 115197 & Fd & $\begin{array}{l}\text { Cardiomyopathy, familial } \\
\text { hypertrophic, } 4 \text { (2) }\end{array}$ & \\
\hline $11 \mathrm{p} 12-\mathrm{p} 11.12$ & GLNN & $\mathbf{P}$ & Galanin & 137035 & Psh, A & ?Galanin deficiency syndrome (1) & $19(G \ln n)$ \\
\hline $11 \mathrm{p} 12-\mathrm{p} 11.12$ & PFM & $\mathbf{L}$ & Parietal foramina & 168500 & $\mathrm{Ch}$ & ?Parietal foramina (2) & \\
\hline $11 \mathrm{p}$ & USH1C & $\mathbf{P}$ & $\begin{array}{l}\text { Usher syndrome-1C } \\
\text { (autosomal recessive, severe) }\end{array}$ & 276904 & Fd & Usher syndrome, type 1C (2) & \\
\hline $11 \mathrm{q}$ & IDDM2 & $\mathbf{L}$ & Insulin-dependent diabetes mellitus- 2 & 125852 & $\mathrm{H}, \mathrm{LD}$ & $\begin{array}{l}\text { ?Insulin-dependent diabetes } \\
\text { mellitus-2 (2) }\end{array}$ & \\
\hline $11 \mathrm{q} 13$ & RT6 & $\mathbf{P}$ & RT6 antigen (rat) homolog & 180840 & REa, A & ?\{Susceptibility to IDDM $\}$ (1) & $7(\mathrm{Rt}-6)$ \\
\hline $11 \mathrm{q} 13$ & SMTN & $\mathbf{P}$ & Somatotrophinoma & 102200 & D & Somatotrophinoma (2) & \\
\hline $11 \mathrm{q} 13$ & UQOR1 & $\mathbf{P}$ & $\begin{array}{l}\text { NADH:ubiquinone oxidoreductase, } 1 \\
\text { mitochondrial }(51 \mathrm{kD})\end{array}$ & 161015 & REa & $\begin{array}{l}\text { ?Mitochondrial complex I deficiency, } \\
252010 \text { (1) }\end{array}$ & \\
\hline $11 \mathrm{q} 13$ & VRNI & $\mathbf{P}$ & $\begin{array}{l}\text { Vitreoretinopathy, neovascular } \\
\text { inflammator }\end{array}$ & 193235 & Fd & $\begin{array}{l}\text { Vitreoretinopathy, neovascular } \\
\text { inflammatory (2) }\end{array}$ & \\
\hline $11 \mathrm{q} 13.5$ & USH1B & $\mathbf{P}$ & $\begin{array}{l}\text { Usher syndrome-1B } \\
\quad \text { (autosomal recessive, severe) }\end{array}$ & 276903 & Fd & Usher syndrome, type 1B (2) & \\
\hline $11 \mathrm{q} 23$ & APOC3 & C & Apolipoprotein C-III & 107720 & REa, RE, F & Hypertriglyceridemia (1) & \\
\hline $11 \mathrm{q} 23$ & $\begin{array}{l}\text { MLL, ALL1, } \\
\text { HRX, TRX1 }\end{array}$ & C & $\begin{array}{l}\text { Myeloid/lymphoid, or mixed-lineage } \\
\text { leukemia; trithorax (Drosophila) } \\
\text { homolog }\end{array}$ & 159555 & $\mathrm{Ch}, \mathrm{RE}$ & $\begin{array}{l}\text { Leukemia, myeloid/lymphoid or } \\
\text { mixed-lineage (2) }\end{array}$ & \\
\hline $\begin{array}{l}11 \mathrm{q} 23-\mathrm{q} 24 \\
11 \mathrm{q} 23.1\end{array}$ & $\begin{array}{l}\text { FLI1 } \\
\text { PORC }\end{array}$ & $\begin{array}{l}\mathbf{C} \\
\mathbf{P}\end{array}$ & $\begin{array}{l}\text { Friend leukemia virus integration } 1 \\
\text { Porphyria, acute, Chester type }\end{array}$ & $\begin{array}{l}193067 \\
176010\end{array}$ & $\begin{array}{l}\text { REa, Ch, A } \\
\text { Fd }\end{array}$ & $\begin{array}{l}\text { Neuroepithelioma, } 133450(1) \\
\text { Porphyria, Chester type (2) }\end{array}$ & \\
\hline
\end{tabular}


Table 1 - contd

\begin{tabular}{|c|c|c|c|c|c|c|c|}
\hline Location & Symbol & Stat & Title & MIM \# & Method & Disorder & Mouse \\
\hline 12pter-p12 & DRPLA & C & Dentatorubro-pallidoluysian atrophy & 125370 & Fd & $\begin{array}{l}\text { Dentatorubro-pallidoluysian } \\
\text { atrophy (3) }\end{array}$ & \\
\hline $12 \mathrm{p} 13.3$ & F8VWF, VWF & C & $\begin{array}{l}\text { Coagulation factor VIII VWF } \\
\text { (von Willebrand factor) }\end{array}$ & 193400 & $\begin{array}{l}\text { A, REa, REb, } \\
\text { Fd }\end{array}$ & von Willebrand disease (1) & $6(V w f)$ \\
\hline $12 \mathrm{p} 13.3-\mathrm{p} 11.2$ & ACLS & $\mathbf{L}$ & Acrocallosal syndrome & 200990 & $\mathrm{Ch}$ & ?Acrocallosal syndrome (2) & \\
\hline $12 p$ & AEM & $\mathbf{P}$ & Ataxia, episodic, with myokymia & 160120 & Fd & Ataxia, episodic, with myokymia (2) & \\
\hline $12 q 11-q 13$ & KRT1, KRTA & C & Keratin-1 & 139350 & H, REa, A & $\begin{array}{l}\text { Epidermolytic hyperkeratosis, } \\
113800 \text { (3) }\end{array}$ & $15(\mathrm{Krt}-2)$ \\
\hline $12 \mathrm{q} 11-\mathrm{q} 13$ & KRT5 & $\mathbf{P}$ & Keratin-5 & 148040 & A, Fd & $\begin{array}{l}\text { Epidermolysis bullosa simplex, } \\
\text { Dowling-Meara type, } 131760 \text { (3); } \\
\text { Epidermolysis bullosa simplex, } \\
\text { Koebner type, 131900 (3); } \\
\text { ?Epidermolysis bullosa, } \\
\text { Weber-Cockayne type, } 131800 \text { (3) }\end{array}$ & \\
\hline $12 \mathrm{q} 12-\mathrm{q} 13$ & CD63, MLA1 & $\mathbf{P}$ & $\begin{array}{l}\text { Antigen CD63 (melanoma } 1 \\
\text { antigen) }\end{array}$ & 155740 & REa, A & $\begin{array}{l}\text { ?Hermansky-Pudlak syndrome, } \\
203300 \text { (1) }\end{array}$ & \\
\hline $12 q 13$ & AQP2 & $\mathbf{P}$ & Aquaporin 2 (collecting duct) & 107777 & A & $\begin{array}{l}\text { ?Diabetes insipidus nephrogenic, } \\
\text { type II, } 125800 \text { (1) }\end{array}$ & \\
\hline $12 q 13.11-q 13.2$ & COL2A1 & C & $\begin{array}{l}\text { Collagen, type II, alpha-1 } \\
\text { polypeptide }\end{array}$ & 120140 & REa, A & $\begin{array}{l}\text { Stickler syndrome, type I (3); } \\
\text { SED congenita (3); } \\
\text { Kniest dysplasia (1); } \\
\text { Achondrogenesis- hypochondrogene } \\
\text { type II (1); Osteoarthrosis, } \\
\text { precocious (3); Wagner syndrome, } \\
\text { type II (1); SMED Strudwick } \\
\text { type (1) }\end{array}$ & esis, \\
\hline 12q14-qter & PPD & $\mathbf{P}$ & $\begin{array}{l}\text { 4-hydroxyphenylpyruvate } \\
\text { dioxygenase }\end{array}$ & 276710 & REa & Tyrosinemia, type III (1) & \\
\hline $12 \mathrm{q} 23-\mathrm{q} 24.1$ & DAR, DWD & $\mathbf{P}$ & Darier disease (keratosis follicularis) & 124200 & Fd & $\begin{array}{l}\text { Darier disease (keratosis } \\
\text { follicularis) (2) }\end{array}$ & \\
\hline $12 \mathrm{q} 24$ & SCA2 & C & $\begin{array}{l}\text { Spinal cerebellar ataxia-2 } \\
\text { (olivopontocerebellar ataxia-2) }\end{array}$ & 183090 & Fd & Spinocerebellar atrophy II (2) & \\
\hline Chr.12 & LYZ & $\mathbf{P}$ & Lysozyme & 153450 & REa & Amyloidosis, renal, 105200 (1) & \\
\hline $13 q 12-q 13$ & DMDA1 & $\mathbf{P}$ & $\begin{array}{l}\text { Duchenne-like muscular dystrophy, } \\
\text { autosomal recessive }\end{array}$ & 253700 & Fd & $\begin{array}{l}\text { Muscular dystrophy, Duchenne-like, } \\
\text { autosomal (2) }\end{array}$ & \\
\hline 13q14 & DBM, D13S25 & $\mathbf{P}$ & Disrupted in B-cell neoplasia & 109543 & $\mathbf{D}$ & $\begin{array}{l}\text { Leukemia, chronic lymphocytic, } \\
\text { B-cell (2) }\end{array}$ & \\
\hline $13 q 14.1-q 14.2$ & RB1, OSRC & C & Retinoblastoma-1 & 180200 & Ch, F, Fd & $\begin{array}{l}\text { Retinoblastoma (3); Osteosarcoma, } \\
259500 \text { (2) }\end{array}$ & $14(\mathrm{Rb}-1)$ \\
\hline $13 q 14.3-q 21.1$ & $\begin{array}{l}\text { ATP7B, WND, } \\
\text { WD }\end{array}$ & $\mathbf{C}$ & $\begin{array}{l}\text { ATPase, Cu++ transporting, } \\
\text { beta polypeptide }\end{array}$ & 277900 & $\mathbf{F}, \mathbf{F d}$ & Wilson disease $(3)$ & \\
\hline $13 q 32-q 34$ & ERCC5 & C & $\begin{array}{l}\text { Excision-repair, complementing } \\
\text { defective, in Chinese hamster, } \\
\text { number } 5\end{array}$ & 133530 & S, A & Xeroderma pigmentosum, group G (1) & \\
\hline Chr.13 & CPB2 & $\mathbf{P}$ & Carboxypeptidase B2 (plasma) & 212070 & Psh & Carboxypeptidase B deficiency (1) & \\
\hline $14 \mathrm{q}$ & DRD & $\mathbf{P}$ & Dystonia, DOPA-responsive & 128230 & Fd & Dystonia, DOPA-responsive (2) & \\
\hline $14 q$ & SPG3 & $\mathbf{P}$ & Spastic paraplegia-3 & 182660 & Fd & Spastic paraplegia-3 (2) & \\
\hline $14 \mathrm{q} 11.1-\mathrm{q} 13$ & HPE4 & $\mathbf{L}$ & Holoprosencephaly-4, semilobar & 142946 & $\mathrm{Ch}$ & ?Holoprosencephaly-4 (2) & \\
\hline $14 \mathrm{q} 11.2$ & TCRA & C & $\begin{array}{l}\text { T-cell antigen receptor, alpha } \\
\text { polypeptide }\end{array}$ & 186880 & $\begin{array}{l}\text { H, REa, A, } \\
\text { REn }\end{array}$ & Leukemia/lymphoma, T-cell (3) & 14 (Tcra) \\
\hline 14q21-q22 & PYGL, PPYL & $\mathbf{P}$ & Phosphorylase, glycogen, liver & 232700 & REb & Glycogen storage disease VI (1) & 12(Pygl) \\
\hline $\begin{array}{l}\text { 14q24-qter } \\
14 \mathrm{q} 24.3\end{array}$ & CAP1 & L & Cataract, anterior polar, 1 & 115650 & $\mathrm{Ch}$ & ?Cataract, anterior polar, I (2) & \\
\hline $\begin{array}{l}14 \mathrm{q} 24.3 \\
14 \mathrm{q} 24.3-\mathrm{q} 31\end{array}$ & AD3 & C & Alzheimer disease-3 & 104311 & Fd & Alzheimer disease-3 (2) & \\
\hline $\begin{array}{l}\text { 14q24.3-q31 } \\
14 \mathrm{q} 24.3 \text {-qter }\end{array}$ & MJD & $\mathbf{P}$ & Machado-Joseph disease & 109150 & Fd & Machado-Joseph disease (2) & \\
\hline $\begin{array}{l}\text { 14q24.3-qter } \\
14 \mathrm{q} 31\end{array}$ & $\begin{array}{l}\text { SCA3 } \\
\text { TSHR }\end{array}$ & $\begin{array}{l}\mathbf{P} \\
\mathbf{C}\end{array}$ & Spinocerebellar ataxia-3 & 183085 & Fd & Spinocerebellar ataxia-3 (2) & \\
\hline $14 \mathrm{q} 31$ & TSHR & C & $\begin{array}{l}\text { Thyroid-stimulating } \\
\text { hormone receptor }\end{array}$ & 275200 & REa, Fd, A & $\begin{array}{l}\text { Hypothyroidism, nongoitrous, due } \\
\text { to TSH resistance (1); Thyroid } \\
\text { adenoma, hyperfunctioning (1); } \\
\text { Graves disease, } 275000 \text { (1) }\end{array}$ & 12 (Tshr) \\
\hline $14 \mathrm{q} 32$ & USH1A, USH1 & $\mathbf{P}$ & Usher syndrome-1A & 276900 & Fd & Usher syndrome, type 1A (2) & \\
\hline $14 \mathrm{q} 32.1$ & $\begin{array}{l}\text { PCI, PLANH3, } \\
\text { PAI3 }\end{array}$ & C & $\begin{array}{l}\text { Protein } C \text { inhibitor (plasminogen } \\
\text { activator inhibitor-3) }\end{array}$ & 227300 & Psh, REn & Protein C inhibitor deficiency (2) & \\
\hline $15 q 11-q 13$ & AHO2 & $\mathbf{L}$ & Albright hereditary osteodystrophy-2 & 103581 & $\mathbf{D}$ & $\begin{array}{l}\text { ?Albright hereditary } \\
\text { osteodystrophy-2 (2) }\end{array}$ & \\
\hline $15 q 11.2-q 12$ & $\begin{array}{l}\text { P, PED, D15S12, } \\
\text { OCA2 }\end{array}$ & C & Pink-eyed dilution, homolog of & 203200 & $\mathrm{D}, \mathrm{REa}, \mathrm{Fd}$ & Albinism, oculocutaneous, type II (3) & $7(p)$ \\
\hline $15 \mathrm{q} 12$ & SNRPN & $\mathbf{P}$ & Small nuclear ribonucleoprotein & 182279 & REa, D & ?Prader-Willi syndrome (1) & 7(Snrpn) \\
\hline $15 q 2$ & CMH3 & $\mathbf{P}$ & $\begin{array}{l}\text { Cardiomyopathy, familial } \\
\text { hypertrophic, } 3 \text { polypeptide } \mathrm{N}\end{array}$ & 115196 & Fd & $\begin{array}{l}\text { Cardiomyopathy, familial } \\
\text { familial hypertrophic, } 3 \text { (2) }\end{array}$ & \\
\hline $15 q 21$ & DA3, CDA3 & $\mathbf{P}$ & Dyserythropoietic anemia, type III & 105600 & Fd & Dyserythropoietic anemia, type III (2) & \\
\hline $\begin{array}{l}15 q 26.1 \\
\text { Chr.15 }\end{array}$ & $\begin{array}{l}\text { BLM, BS } \\
\text { XPF }\end{array}$ & $\begin{array}{l}\text { C } \\
\text { L }\end{array}$ & $\begin{array}{l}\text { Bloom syndrome } \\
\text { Xeroderma pigmentosum, } \\
\text { complementation group F }\end{array}$ & $\begin{array}{l}210900 \\
278760\end{array}$ & $\begin{array}{l}M, L D \\
M\end{array}$ & $\begin{array}{l}\text { Bloom syndrome (2) } \\
\text { ?Xeroderma pigmentosum, type F (2) }\end{array}$ & \\
\hline $16 \mathrm{p} 13.3$ & CATM & $\mathbf{P}$ & $\begin{array}{l}\text { Cataract, congenital, with } \\
\text { microphthalmia }\end{array}$ & 156850 & $\mathrm{Ch}$ & $\begin{array}{l}\text { Cataract, congenital, with } \\
\text { microphthalmia (2) }\end{array}$ & \\
\hline $16 \mathrm{p} 13$ & TSC2 & C & Tuberous sclerosis- 2 & 191092 & Fd & Tuberous sclerosis-2 (2) & \\
\hline $16 \mathrm{q} 21$ & BBS2 & $\mathbf{P}$ & Bardet-Biedl syndrome-2 & 209900 & & Bardet-Biedl syndrome-2 (2) & \\
\hline $16 \mathrm{q} 24.3$ & GALNS, MPS4A & C & $\begin{array}{l}\mathrm{N} \text {-acetylgalactosamine-6-sulfate } \\
\text { sulfatase }\end{array}$ & 253000 & A, Psh & Mucopolysaccharidosis IVA (3) & \\
\hline $17 \mathrm{p} 11.2$ & PMP22, CMT1A & C & Peripheral myelin protein-22 & 118220 & Fd, D, A & $\begin{array}{l}\text { Charcot-Marie-Tooth neuropathy, } \\
\text { slow nerve conduction type Ia (2); } \\
\text { Neuropathy, recurrent, with } \\
\text { pressure palsies, } 162500 \text { (3); } \\
\text { Dejerine-Sottas disease, } \\
\text { PMP22 related, } 145900 \text { (3) }\end{array}$ & \\
\hline $17 q 11.2$ & NF1, VRNF, WSS & $\mathbf{C}$ & $\begin{array}{l}\text { Neurofibromatosis, type } 1 \\
\text { (neurofibromatosis, von } \\
\text { Recklinghausen disease, } \\
\text { Watson syndrome) }\end{array}$ & 162200 & $\begin{array}{r}\text { Fd, EM, } \\
\text { Ch, F }\end{array}$ & $\begin{array}{l}\text { PMP22 related, } 145900(3) \\
\text { Neurofibromatosis, type I (3); } \\
\text { Watson syndrome, } 193520 \text { (3) }\end{array}$ & $11(\mathrm{Tr})$ \\
\hline
\end{tabular}


Table 1 - contd

\begin{tabular}{|c|c|c|c|c|c|c|c|}
\hline Location & Symbol & Stat & Title & MIM \# & Method & Disorder & Mouse \\
\hline $17 q 11.2-q 24$ & MHS2 & $\mathbf{P}$ & $\begin{array}{l}\text { Malignant hyperthermia } \\
\text { susceptibility- } 2\end{array}$ & 154275 & Fd & $\begin{array}{l}\text { Malignant hyperthermia } \\
\text { susceptibility-2, } 145600 \text { (2 }\end{array}$ & \\
\hline $17 q 12-q 21$ & $\begin{array}{l}\text { EDH17B1, } \\
\text { EDHB17A }\end{array}$ & C & Estradiol 17-beta-dehydrogenase-1 & 264300 & A, REa & $\begin{array}{l}\text { Pseudohermaphroditism, male, } \\
\text { with gynecomastia (1); Polycystic } \\
\text { ovarian disease (1) }\end{array}$ & \\
\hline $17 q 12-q 21$ & EPPK, KRT9 & C & $\begin{array}{l}\text { Epidermolytic palmoplantar } \\
\text { keratoderma }\end{array}$ & 144200 & $\mathrm{Fd}, \mathrm{REa}$ & $\begin{array}{l}\text { Epidermolytic palmoplantar } \\
\text { keratoderma (3) }\end{array}$ & \\
\hline $17 q 21-q 22$ & $\begin{array}{l}\text { EPB3, EMPB3, } \\
\text { AE1 }\end{array}$ & $\mathrm{C}$ & $\begin{array}{l}\text { Erythrocyte surface protein band } 3 \\
\text { (anion exchanger-1) }\end{array}$ & 109270 & $\begin{array}{l}\text { REa, RE, } \\
\text { Fd, A }\end{array}$ & $\begin{array}{l}\text { [Acanthocytosis, one form] (1); } \\
\text { [Elliptocytosis, Malaysian- } \\
\text { Melanesian type] (1); } \\
\text { Spherocytosis, hereditary (3) }\end{array}$ & \\
\hline $17 q 21-q 22$ & PENT, PNMT & C & $\begin{array}{l}\text { Phenylethanolamine } \\
\mathrm{N} \text {-methyltransferase }\end{array}$ & 171190 & REa, Fd & ?Hypertension, essential, 145500 (1) & \\
\hline $17 \mathrm{q} 21.31-\mathrm{q} 22.0$ & $5 \mathrm{COL} 1 \mathrm{~A} 1$ & C & Collagen I, alpha-1 polypeptide & 120150 & C, M, A, REa & $\begin{array}{l}\text { Osteogenesis imperfecta, } 4 \text { clinical } \\
\text { forms, } 166200,166210,259420 \text {, } \\
166220 \text { (3); Ehlers-Danlos } \\
\text { syndrome, type VIIA1, } 130060 \text { (3); } \\
\text { Osteoporosis, idiopathic, } \\
166710 \text { (3) }\end{array}$ & $11($ Cola-1) \\
\hline $17 q 21.32$ & $\begin{array}{l}\text { ITGA2B, GP2B, } \\
\text { CD41B }\end{array}$ & C & $\begin{array}{l}\text { Integrin, alpha IIB (platelet } \\
\text { glycoprotein IIb of IIb/IIIa } \\
\text { complex, antigen CD41B) }\end{array}$ & 273800 & $\begin{array}{l}\text { A, REb, REa, } \\
\text { RE, F, LD }\end{array}$ & $\begin{array}{l}\text { Glanzmann thrombasthenia, type A (1); } \\
\text { Thrombocytopenia, neonatal } \\
\text { alloimmune (1) }\end{array}$ & \\
\hline $17 q 23$ & DCP1, ACE1 & $\mathrm{C}$ & $\begin{array}{l}\text { Dipeptidyl carboxypeptidase-1 } \\
\text { (angiotensin I converting enzyme) }\end{array}$ & 106180 & $\mathrm{~A}, \mathrm{H}, \mathrm{Fd}$ & $\begin{array}{l}\text { \{Myocardial infarction, susceptibility } \\
\text { to }\} \text { (3) }\end{array}$ & \\
\hline $17 q 23$ & GAA & C & Glucosidase, acid alpha- & 232300 & $S, A, D, C$ & Glycogen storage disease, type II (1) & \\
\hline $17 \mathrm{q} 24.3-\mathrm{q} 25.1$ & $\begin{array}{l}\text { CMPD1, CMD1, } \\
\text { SRA1 }\end{array}$ & C & $\begin{array}{l}\text { Campomelic dysplasia-1 } \\
\quad(\text { sex reversal, autosomal, 1) }\end{array}$ & 211970 & $\mathrm{Ch}$ & Campomelic dysplasia-1 (2) & ?11(Ts) \\
\hline $17 q 25$ & RSS & $\mathbf{L}$ & Russell-Silver syndrome & 270050 & $\mathrm{Ch}$ & ?Russell-Silver syndrome (2) & \\
\hline 18pter-q11 & HPE1 & $\mathbf{L}$ & Holoprosencephaly-1, alobar & 236100 & $\mathrm{Ch}$ & ?Holoprosencephaly-1 (2) & \\
\hline $18 \mathrm{p} 11.2$ & MC2R & $\mathbf{P}$ & $\begin{array}{l}\text { Melanocortin-2 receptor } \\
\text { (ACTH receptor) }\end{array}$ & 202200 & A & $\begin{array}{l}\text { Glucocorticoid deficiency, due to } \\
\text { ACTH unresponsiveness (1) }\end{array}$ & \\
\hline $18 \mathrm{p}$ & NPC & C & Niemann-Pick disease, type $\mathrm{C}$ & 257220 & $\mathrm{Ch}, \mathrm{H}, \mathrm{Fd}, \mathbf{M}$ & Niemann-Pick disease, type C (2) & $18(\mathrm{spm})$ \\
\hline $18 \mathrm{q} 22$-qter & MS1 & L & Multiple sclerosis & 126200 & Fd, LD & $\begin{array}{l}\text { \{?Multiple sclerosis, susceptibility } \\
\text { to\} (2) }\end{array}$ & \\
\hline Chr.18 & FEO & $\mathbf{P}$ & Familial expansile osteolysis & 174810 & Fd & Familial expansile osteolysis (2) & \\
\hline $19 \mathrm{p} 13.3$ & HHC2, FHH2 & $\mathbf{P}$ & Hypocalciuric hypercalcemia, type 2 & 145981 & Fd & $\begin{array}{l}\text { Hypocalciuric hypercalcemia, } \\
\text { type II (2) }\end{array}$ & \\
\hline 19p13.3-p13.2 & EPOR & C & Erythropoietin receptor & 133171 & A, REa, $\mathrm{H}$ & [Erythrocytosis, familial], 133100 (2) & 9(Epor) \\
\hline $19 \mathrm{p} 13.2-\mathrm{q} 13.3$ & LPSA, D19S381E & $\mathbf{P}$ & $\begin{array}{l}\text { Oncogene liposarcoma (DNA } \\
\text { Segment, single copy, expressed, } \\
\text { probes MC15, MC6) }\end{array}$ & 164953 & A & Liposarcoma (1) & \\
\hline 19 cen-q13.2 & $\mathrm{AD} 2$ & C & Alzheimer disease-2 (late-onset) & 104310 & Fd & Alzheimer disease-2, late onset (2) & \\
\hline $19 q 12$ & CASIL & $\mathbf{P}$ & $\begin{array}{l}\text { Cerebral arteriopathy with } \\
\text { subcortical infarcts and } \\
\text { leukoencephalopathy }\end{array}$ & 125310 & $\mathrm{Fd}$ & $\begin{array}{l}\text { Cerebral arteriopathy with subcortical } \\
\text { infarcts and leukoencephalopathy (2) }\end{array}$ & \\
\hline $19 \mathrm{q} 12$ & MED & $\mathbf{P}$ & Multiple epiphyseal dysplasia & 132400 & Fd & Multiple epiphyseal dysplasia (2) & \\
\hline $19 \mathrm{q} 12$ & PSACH & $\mathrm{C}$ & Pseudoachondroplastic dysplasia & 177150 & Fd & Pseudoachondroplastic dysplasia (2) & \\
\hline $19 q 12-q 13$ & MHP & $\mathbf{P}$ & Migraine, familial hemiplegic & 141500 & Fd & Migraine, familial hemiplegic (2) & \\
\hline $19 q 13.1$ & $\begin{array}{l}\text { RYR1, RYDR, } \\
\text { MHS, CCO }\end{array}$ & $\mathrm{C}$ & Ryanodine receptor-1 (skeletal) & 180901 & $\mathrm{~A}, \mathrm{Fd}, \mathrm{H}$ & $\begin{array}{l}\text { Malignant hyperthermia } \\
\text { susceptibility-1, } 145600(3) ; \\
\text { Central core disease, } 117000 \text { (3) }\end{array}$ & 7 (Ryr) \\
\hline $19 q 13.1-q 13.2$ & AKT2 & $\mathbf{P}$ & $\begin{array}{l}\text { Murine thymoma viral (v-akt) } \\
\text { homolog- } 2\end{array}$ & 164731 & $\mathbf{A}$ & Ovarian carcinoma, $167000(2)$ & \\
\hline $19 \mathrm{q} 13.2-\mathrm{q} 13.3$ & PVS & C & Polio virus sensitivity & 173850 & S, A & $\{$ Polio, susceptibility to $\}(2)$ & 9(Pvs) \\
\hline $19 q 13.3$ & GYS, GCGS & $\mathrm{C}$ & Glycogen synthase & 138570 & REa, A & $\begin{array}{l}\text { \{Non-insulin dependent diabetes } \\
\text { mellitus, susceptibility to\} }(2)\end{array}$ & \\
\hline Chr.19 & ETFB & $\mathbf{P}$ & $\begin{array}{l}\text { Electron transfer flavoprotein, beta } \\
\text { polypeptide }\end{array}$ & 130410 & REa & Glutaricaciduria, type IIB (2) & \\
\hline $20 \mathrm{p} 12$ & BMP2, BMP2A & $\mathrm{C}$ & Bone morphogenetic protein-2 & 112261 & $\mathrm{H}, \mathrm{REa}, \mathrm{A}$ & $\begin{array}{l}\text { ?Fibrodysplasia ossificans } \\
\text { progressiva (1) }\end{array}$ & 2(Bmp2a) \\
\hline $20 \mathrm{q} 13.2$ & GNAS1, GNAS, & $\mathrm{C}$ & $\begin{array}{l}\text { Guanine nucleotide-binding protein } \\
\text { (G protein), alpha-stimulating } \\
\text { activity polypeptide-1 GPSA }\end{array}$ & 139320 & $\mathrm{REa}, \mathrm{H}, \mathrm{A}, \mathrm{Fd}$ & $\begin{array}{l}\text { Pseudohypoparathyroidism, type Ia, } \\
103580 \text { (1); McCune-Albright } \\
\text { polyostotic fibrous dysplasia, } \\
174800 \text { (1); Somatotrophinoma (1) }\end{array}$ & 2(Gnas) \\
\hline $20 \mathrm{q} 13.31$ & PCK1 & C & $\begin{array}{l}\text { Phosphoenolpyruvate } \\
\text { carboxykinase-1 (soluble) }\end{array}$ & 261680 & $\mathrm{REa}, \mathrm{A}, \mathrm{Fd}$ & $\begin{array}{l}\text { ?Hypoglycemia due to PCK1 ) } \\
\text { deficiency (1) }\end{array}$ & $2($ Pck1) \\
\hline $21 \mathrm{q} 22.1$ & SOD1, ALS1 & C & Superoxide dismutase- 1 , soluble & 147450 & $\mathrm{~S}, \mathrm{D}, \mathrm{Fd}$ & $\begin{array}{l}\text { Amytrophic lateral sclerosis, due to } \\
\text { SOD1 deficiency, } 105400 \text { (3) }\end{array}$ & $16($ Sod-1) \\
\hline $22 \mathrm{q} 12.2$ & $\mathrm{NF} 2, \mathrm{ACN}$ & $\mathrm{C}$ & $\begin{array}{l}\text { Neurofibromatosis-2 } \\
\quad \text { (bilateral acoustic neuroma) }\end{array}$ & 101000 & $\begin{array}{l}\text { RE, F, Ch, } \\
\text { D, Fd }\end{array}$ & $\begin{array}{l}\text { Neurofibromatosis, type } 2 \text { (3); } \\
\text { Meningioma, NF2-related (3) }\end{array}$ & \\
\hline $22 q 13.1$ & $\begin{array}{l}\text { CYP2D@, } \\
\text { CYP2D, P450C2D }\end{array}$ & C & Cytochrome P450, subfamily IID & 124030 & F, Fd, Psh, A & $\begin{array}{l}\text { \{?Parkinsonism, susceptibility to }\} \text { (1); } 1 \\
\text { Debrisoquine sensitivity (1) }\end{array}$ & 15(Сур2d) \\
\hline Xpter-p22.32 & GCFX, SS & $\mathbf{P}$ & Growth control factor, X-linked & 312865 & Fd & Short stature (2) & \\
\hline Xpter-p22.2 & CFND & $\mathrm{L}$ & Craniofrontonasal dysplasia & 304110 & $\mathrm{Ch}$ & ?Craniofrontonasal dysplasia (2) & \\
\hline $\mathrm{Xp} 22.3$ & OASD & $\vec{P}$ & $\begin{array}{l}\text { Ocular albinism and sensorineural } \\
\text { deafness }\end{array}$ & 300650 & Fd & $\begin{array}{l}\text { Ocular albinism with sensorineural } \\
\text { deafness (2) }\end{array}$ & \\
\hline $\mathrm{Xp21.1}$ & RP3 & C & $\begin{array}{r}\text { Retinitis pigmentosa-3 } \\
\text { (X-linked recessive) }\end{array}$ & 312610 & Fd, D & Retinitis pigmentosa-3 (2) & \\
\hline $\mathrm{Xp} 21$ & SRS, MRSR & $\mathbf{P}$ & $\begin{array}{l}\text { Snyder-Robinson X-linked mental } \\
\text { retardation syndrome }\end{array}$ & 309583 & Fd & $\begin{array}{l}\text { Mental retardation, Snyder-Robinson } \\
\text { type (2) }\end{array}$ & \\
\hline Xp11.4 & NDP, ND & $\mathrm{C}$ & Norrie disease (pseudoglioma) & 310600 & Fd, D & $\begin{array}{l}\text { Norrie disease (3); Exudative } \\
\text { vitreoretinopathy, X-linked, } \\
305390 \text { (3) }\end{array}$ & \\
\hline Xp11.23 & MAOA & C & Monoamine oxidase $\mathrm{A}$ & 309850 & $\begin{array}{l}\text { Fd, REa, D, A, } \\
\text { REn }\end{array}$ & , Brunner syndrome (3) & $\mathrm{X}$ (Maoa) \\
\hline Xp11.2 & SSRC & C & Sarcoma, synovial & 312820 & $\mathrm{Ch}, \mathbf{R E}, \mathrm{A}$ & Sarcoma, synovial (2) & \\
\hline
\end{tabular}


Table 1 - contd

\begin{tabular}{|c|c|c|c|c|c|c|c|}
\hline Location & Symbol & Stat & Title & MIM \# & Method & Disorder & Mouse \\
\hline Xpl1 & MRXA & $\mathbf{L}$ & $\begin{array}{l}\text { Mental retardation, } X \text {-linked } \\
\text { nonspecific, with aphasia }\end{array}$ & 309545 & Fd & $\begin{array}{l}\text { ?Mental retardation, } \mathrm{X} \text {-linked } \\
\text { nonspecific, with aphasia (2) }\end{array}$ & \\
\hline Xq12-q13 & $\begin{array}{l}\text { ATP7A, MNK, } \\
\text { MK }\end{array}$ & C & $\begin{array}{l}\text { ATPase, } \mathrm{Cu}++ \text { transporting, } \\
\text { alpha polypeptide }\end{array}$ & 309400 & Fc, $X / A, H$ & Menkes disease (2) & $\mathbf{X}$ (Mo) \\
\hline$X q 12-q 21$ & JMS & $\mathbf{P}$ & Juberg-Marsidi syndrome & 309590 & Fd & Juberg-Marsidi syndrome (2) & \\
\hline Xq12-q21.31 & ATRX, ATR2 & $\mathbf{P}$ & $\begin{array}{l}\text { Alpha-thalassemia/mental } \\
\text { retardation syndrome, } \\
\text { X-linked }\end{array}$ & 301040 & Fd & $\begin{array}{l}\text { Alpha-thalassemia/mental retardation } \\
\text { syndrome, type } 2(2)\end{array}$ & \\
\hline Xq13 & ASAT & $\mathbf{L}$ & $\begin{array}{l}\text { Anemia, sideroblastic, with } \\
\text { spinocerebellar ataxia }\end{array}$ & 301310 & Fd & $\begin{array}{l}\text { ?Anemia, sideroblastic, with } \\
\text { spinocerebellar ataxia (2) }\end{array}$ & \\
\hline Xq13 & $\begin{array}{l}\text { IL2RG, SCIDX1, } \\
\text { SCIDX, IMD4 }\end{array}$ & C & Interleukin-2 receptor, gamma & 308380 & Fd & $\begin{array}{l}\text { Severe combined immunodeficiency, } \\
\text { X-linked, } 300400 \text { (3) }\end{array}$ & \\
\hline Xq13 & PHKA1 & C & $\begin{array}{l}\text { Phosphorylase kinase, muscle, } \\
\text { alpha polypeptide }\end{array}$ & 311870 & REa, A, REn & ?Muscle glycogenosis (1) & $\mathbf{X}($ Phka) \\
\hline Xq13.1 & $\begin{array}{l}\text { GJB1, CX32 } \\
\text { CMTX1 }\end{array}$ & C & $\begin{array}{l}\text { Gap junction protein, beta-1, } 32 \mathrm{kD} \\
\text { (connexin } 32 \text { ) }\end{array}$ & 304040 & REa, Fd & $\begin{array}{l}\text { Charcot-Marie-Tooth neuropathy, } \\
\text { X-linked-1, dominant, } 302800 \text { (3) }\end{array}$ & $\mathbf{X}(\mathrm{Gjb} 1)$ \\
\hline $\mathrm{Xq13.1}$ & $\begin{array}{l}\text { RPS4X, CCG2, } \\
\text { SCAR }\end{array}$ & C & Ribosomal protein S4, X-linked & 312760 & A, REa, REn & Turner syndrome (1) & $X(\operatorname{Rps} 4 x)$ \\
\hline $\mathrm{Xq21.1-q21.31}$ & CPX & C & Cleft palate and/or ankyloglossia & 303400 & Fd, D & Cleft palate, $\mathrm{X}$-linked (2) & \\
\hline $\mathrm{Xq21.3-q22}$ & $\begin{array}{l}\text { BTK, AGMX1, } \\
\text { IMDI, XLA, AT }\end{array}$ & C & $\begin{array}{l}\text { Bruton agammaglobulinemia } \\
\text { tyrosine kinase }\end{array}$ & 300300 & H, Fd, A & $\begin{array}{l}\text { Agammaglobulinemia, type } 1 \text {, } \\
\text { X-linked ( } 3\end{array}$ & X(xid, Btp) \\
\hline Xq22 & COL4A6 & $\mathbf{P}$ & $\begin{array}{l}\text { Collagen, type IV, alpha- } 6 \\
\text { polypeptide }\end{array}$ & 303631 & REn & $\begin{array}{l}\text { Leiomatosis, diffuse (1); ?Alport } \\
\text { syndrome, X-linked, type } 2 \text { (1) }\end{array}$ & \\
\hline Xq22-q28 & AIH3 & $\mathbf{L}$ & $\begin{array}{l}\text { Amelogenesis imperfecta-3, } \\
\text { hypomaturation or hypoplastic } \\
\text { type hypoplastic type }\end{array}$ & 301201 & Fd & $\begin{array}{l}\text { ?Amelogenesis imperfecta-3, } \\
\text { hypoplastic type ( } 2)\end{array}$ & \\
\hline $\mathrm{Xq22.1}$ & PIGA & $\mathbf{P}$ & Phosphatidylinositol glycan class A & 311770 & A & $\begin{array}{l}\text { Paroxysmal nocturnal } \\
\text { hemoglobinuria (3) }\end{array}$ & \\
\hline $\mathrm{Xq} 25-\mathrm{q} 26$ & HTX & $\mathbf{P}$ & Heterotaxy, X-linked visceral & 306995 & Fd & Heterotaxy, X-linked visceral (2) & \\
\hline $\mathrm{Xq} 25-\mathrm{q} 26.1$ & TAS & $\mathbf{P}$ & Thoracoabdominal syndrome & 313850 & Fd & Thoracoabdominal syndrome (2) & \\
\hline $\mathrm{Xq} 26$ & $\begin{array}{l}\text { CD40LG, HIGM1, } \\
\text { IGM }\end{array}$ & , C & $\begin{array}{l}\text { CD40 antigen ligand (hyper IgM } \\
\text { syndrome) }\end{array}$ & 308230 & Fd, A, Psh & $\begin{array}{l}\text { Immunodeficiency, X-linked, } \\
\text { with hyper-IgM (3) }\end{array}$ & $\mathrm{X}(\mathrm{CD} 401)$ \\
\hline Xq26 & GUST & $\mathbf{P}$ & $\begin{array}{l}\text { Gustavson mental retardation } \\
\text { syndrome (with microcephaly, } \\
\text { optic atrophy, deafness) }\end{array}$ & 309555 & Fd & Gustavson syndrome (2) & \\
\hline $\mathrm{Xq} 26$ & SDYS, SGB & C & Simpson dysmorphia syndrome & 312870 & Fd & Simpson-Galabi-Behmel syndrome (2) & \\
\hline $\mathrm{Xq26}$ & SHFD2 & $\mathbf{P}$ & Split-hand/split-foot deformity, type 2 & 313350 & $\mathbf{F d}$ & $\begin{array}{l}\text { Split-hand/split-foot deformity, } \\
\text { type } 2(2)\end{array}$ & \\
\hline $\mathrm{Xq28}$ & DKC & C & Dyskeratosis congenita & 305000 & $\mathrm{Fd}$ & Dyskeratosis congenita (2) & \\
\hline $\mathrm{Xq} 28$ & EFE2, BTHS & $\mathbf{C}$ & $\begin{array}{l}\text { Endocardial fibroelastosis-2 } \\
\text { (Barth syndrome; cardioskeletal } \\
\text { myopathy with neutropenia and } \\
\text { abnormal mitochondria) }\end{array}$ & 302060 & $\mathbf{F d}$ & $\begin{array}{l}\text { Endocardial fibroelastosis-2 (2); } \\
\text { Barth syndrome (2) }\end{array}$ & \\
\hline $\mathrm{Xq} 28$ & FRAXE, FMR2 & $\mathbf{P}$ & Fragile site, $\mathrm{X}$-linked, $\mathrm{E}$ & 309548 & Ch, REn & $\begin{array}{l}\text { Mental retardation, } \mathrm{X} \text {-linked, } \\
\text { FRAXE type (3) }\end{array}$ & \\
\hline $\mathrm{Xq} 28$ & $\begin{array}{l}\text { L1CAM, CAML1, } \\
\text { HSAS1, HSAS }\end{array}$ & C & L1 cell adhesion molecule & 308840 & A, RE, $\mathrm{H}$ & $\begin{array}{l}\text { Hydrocephalus due to aqueduct of } \\
\text { Sylvius, } 307000 \text { (3) }\end{array}$ & $\mathbf{X}($ Ll cam $)$ \\
\hline Yp11.3 & TDF, SRY & C & $\begin{array}{l}\text { Testis determining factor } \\
\quad(\text { sex-determining region } \mathrm{Y})\end{array}$ & 480000 & $\mathrm{Ch}, \mathrm{Fd}$ & Gonadal dysgenesis, XY type (1) & Y(Tdy, Sry) \\
\hline
\end{tabular}


Table 2 The morbid anatomy of the human genome (by disorder)

\begin{tabular}{ll} 
Disorder & Location \\
\hline [Acanthocytosis, one form] (1) & 17q21- 922
\end{tabular}

[Acanthocytosis, one form] (1).............................................. 17q21-q22 Achondrogenesis-hypochondrogenesis, type II (1) ................ 12q13.11-q13.2 ?Acrocallosal syndrome (2) .................................................12p13.3-p11.2 ?Acrofacial dysostosis, Nager type (2) ..............................................9q32

Adrenal hyperplasia, congenital, due to 11-beta-hydroxylase

deficiency (1)

Adrenal hyperplasia, congenital, due to 17-alpha-hydroxylase

deficiency (1)....

Agammaglobulinemia

Albinism, brown, 203290 (1) ................................................... 9p23

Albinism, oculocutaneous, type II (3) ………........................... 15q11.2-q12

Albinism, oculocutaneous, type II (3) ……..................... 15q11.2-q12

Aldosteronism, glucocorticoid-remediable (1) ………..................... 8q2

Alkaptonuria (2) ................................................................3q

?Alport syndrome, X-linked, type 2 (1) ............................................ Xq22

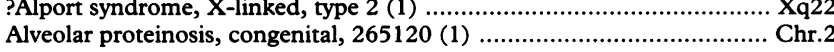

Alzheimer disease-2, late onset (2) ........................................ 19cen-q13.2

Alzheimer disease-3 (2) ....................................................... 14q24.3

?Amelogenesis imperfecta-3, hypoplastic type (2) .......................... Xq22-q28

[AMP deaminase deficiency, erythrocytic] (1) ........................11 pter-p13

Amyloidosis, hereditary renal, 105200 (1) …....................................4q28

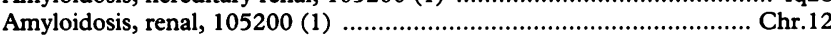

Amyotrophic lateral sclerosis, juvenile (2) ................................. 2q33-q35

Amytrophic lateral sclerosis, due to SOD1 deficiency, 105400 (3) ..... 21q22.1

?Anemia, sideroblastic, with spinocerebellar ataxia (2) .......................... Xq13

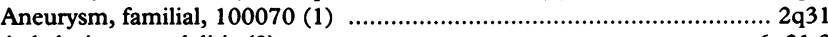

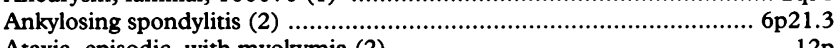

Ataxia, episodic, with myokymia (2) ............................................12p

\{?Atherosclerosis, susceptibility to\} (3) ..................................... 8p21-p12

Bardet-Biedl syndrome-2 (2) ................................................ 16q21

Barth syndrome (2) ................................................................ Xq28

Basal cell carcinoma (1) ............................................................ 5q13.3

\{Beryllium disease, chronic, susceptibility to\} (1) ........................ 6p21.3

3-beta-hydroxysteroid dehydrogenase, type II, deficiency (3) ............. 1p 13.1

Blepharophimosis, epicanthus inversus and ptosis (2) ................. 3q22-q23

Bloom syndrome (2) .......................................................... 15q26.1

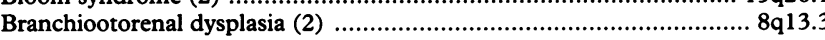

Breast cancer (1) ...................................................................6225.1

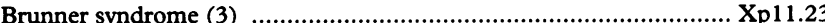

Campomelic dysplasia-1 (2) ............................................. 17q24.3-q25.1

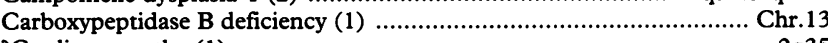

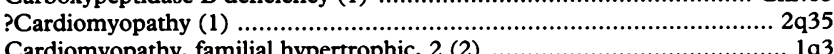

Cardiomyopathy, familial hypertrophic, 2 (2) …........................... 19q

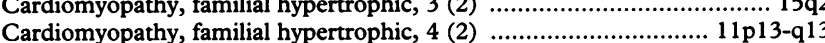

Cardiomyopathy, familial hypertrophic, 4 (2) ...................... 11 p13-q13

?Cataract, anterior polar, I (2) ...................................................... 14q24-qte

Cataract, congenital, with microphthalmia (2) ............................ 16p13.3

CD3, zeta chain, deficiency (1) ............................................. 1q23-q21.1

CD59 deficiency (3) ................................................................ $11 \mathrm{p} 13$

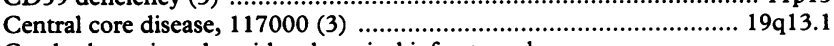

Cerebral arteriopathy with subcortical infarcts and

leukoencephalopathy (2)

Charcot-Marie-Tooth disease, type II (2)

Charcot-Marie-Tooth disease, type IVA (2)

Charcot-Marie-Tooth neuropathy, slow nerve

conduction type Ia (2)

Charcot-Marie-Tooth neuropathy, slow nerve

conduction type $\mathrm{Ib}, 118200$ (3)

Charcot-Marie-Tooth neuropathy, X-linked-1,

dominant, 302800 (3)

Chloride diarrhea, congenital (2)

?Chondrodysplasia punctata, rhizomelic (2)

\{Chronic infections, due to opsonin defect\} (1)

Cleft palate, X-linked (2)

... 19q12

$1 \mathrm{p} 36-\mathrm{p} 35$

8q13-q21.1

CMO II deficiency (1)

Cockayne syndrome-2, late onset, 216410 (2)

Colon cancer, familial, nonpolyposis type 1 (3)

type (2) …........... 5q22-q33.3

I (2) .............................. 5q22-q33.3

Corneal dystrophy, lattice type I, 122200 (2) ............................ 5q22-q33.3

?Craniofrontonasal dysplasia (2) ........................................... Xpter-p22.2

Craniosynostosis, type 2 (3) ..................................................... 5q34-q35

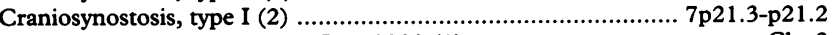

Crigler-Najjar syndrome, type I, 218800 (1) .................................. Chr.2

?Cystinuria, 220100 (1) ........................................................ 2pter-q32.3

Darier disease (keratosis follicularis) (2) .................................. 12q23-q24.1

Debrisoquine sensitivity (1) …................................................. 22q13.1

Dejerine-Sottas disease, myelin P(0)-related, 145900 (3) ........................ 1q22

Dejerine-Sottas disease, PMP22 related, 145900 (3) ................... 17p11.2

Dentatorubro-pallidoluysian atrophy (3) ............................... 12pter-p12

?Diabetes insipidus nephrogenic, type II, 125800 (1) ........................ 12q13

Dysautonomia, familial (2) ....................................................... 9q31-q33

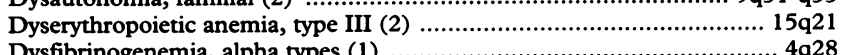

Disorder

Location

Dyskeratosis congenita (2) ................................................................28

Dystonia, DOPA-responsive (2) ............................................... 14q

Ehlers-Danlos syndrome, type IV, 130050 (3) ................................... 2q31

Ehlers-Danlos syndrome, type VIIA1, 130060 (3) ............... 17q21.31-q22.05

[Elliptocytosis, Malaysian-Melanesian type] (1) …….................. 17q21-q22

Endocardial fibroelastosis-2 (2) ......... Xq28

Epidermolysis bullosa dystrophica, dominant, 131750 (3) ................... 3p21.3

Epidermolysis bullosa dystrophica, recessive, 226600 (3) ................ 3p21.3

Epidermolysis bullosa simplex, Dowling-Meara type, 131760 (3) .. 12q11-q13

Epidermolysis bullosa simplex, Koebner type, 131900 (3) ............. 12q11-q13

?Epidermolysis bullosa, Weber-Cockayne type, 131800 (3) .......... 12q11-q13

Epidermolytic hyperkeratosis, 113800 (3) ……........................ 12q11-q13

Epidermolytic palmoplantar keratoderma (3) ……....................... 17q12-q21

Epilepsy, benign neonatal, type 2 (2)

[Erythrocytosis, familial], 133100 (2) ………......................... 19p13.3-p13.2

Exostoses, multiple, type 1 (2) ..................................... 8q24.11-q24.13

Exudative vitreoretinopathy, X-linked, 305390 (3) ........................... Xp1 1.4

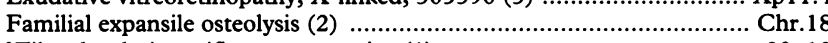

?Fibrodysplasia ossificans progressiva (1) ........................................ 20p12

Fibromuscular dysplasia of arteries, 135580 (1) ................................ 2q31

Friedreich-like ataxia, due to vitamin E deficiency (2) ............................ 8

Fukuyama type congenital muscular dystrophy (2) ..................... 9q31-q33

?Galanin deficiency syndrome (1) ....................................11 1 12-p11.12

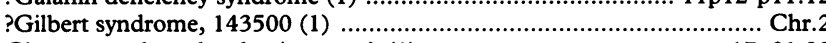

Glanzmann thrombasthenia, type A (1) ................................. 17q21.32

Glaucoma, primary open angle, juvenile-onset (2) ..................... 1q21-q31

Glucocorticoid deficiency, due to ACTH unresponsiveness (1) ........ 18p11.2

Glutaricacidemia type IIC (3) ................................................ 4q32-qter

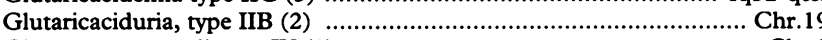

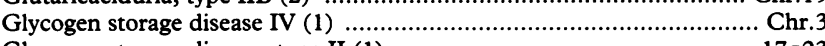

Glycogen storage disease, type II (1) ........................................ 17q23

Glycogen storage disease VI (1) ...................................... 14q21-q22

?Glycoprotein Ia deficiency (2) …….................................... 5q23-q31

GM2-gangliosidosis, AB variant (1) ……................................. 5q32-q33.1

Goiter, adolescent multinodular (1) ................................. 8q24.2-q24.3

Goiter, nonendemic, simple (1) ...................................... 8q24.2-q24.3

Gonadal dysgenesis, $\mathrm{XY}$ type (1) ……………............................ Yp1 1.3

Graves disease, 275000 (1) .....................................................14q31

Gustavson syndrome (2) .........................................................24

?Hartnup disease, 234500 (1) .................................................. 2pter-q32.3

Hereditary hemorrhagic telangiectasia (2) ........................................ 9q

?Hermansky-Pudlak syndrome, 203300 (1) ............................... 12q12-q13

Heterotaxy, X-linked visceral (2) …............................................... X25-q26

Holoprosencephaly, type 3 (2) ….............................................. 7q36

?Holoprosencephaly-1 (2) ................................................. 18pter-q11

?Holoprosencephaly-4 (2) .............................................. 14q11.1-q13

Homocystinuria due to MTHFR deficiency (3) ............................... 1p36.3

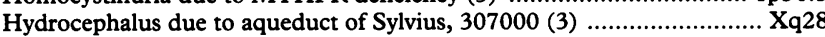

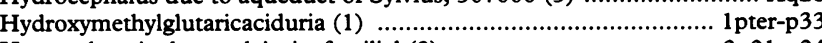

Hypercalcemia, hypocalciuric, familial (3) .................................... 3q21-q24

Hyperparathyroidism, neonatal 239200 (3) ............................... 3q21-q24

Hyperphenylalaninemia due to 4a-carbinolamine dehydratase

deficiency, 264070 (1) ..................................................... 10q21-q22

?Hypertension, essential, 145500 (1) ........................................ 17q21-q22

\{Hypertension, essential, susceptibility to\} (3) ............................... 1 q42-q43

Hypertriglyceridemia (1) ........................................................... 11 1q23

Hypocalciuric hypercalcemia, type II (2) ................................... 19p13.3

?Hypoglycemia due to PCK1 deficiency (1) ................................. 20q13.31

Hypothyroidism, hereditary congenital (1) ......................... 8q24.2-q24.3

Hypothyroidism, nongoitrous, due to TSH resistance (1) ....................14q31

Immunodeficiency, X-linked, with hyper-IgM (3) ................................ Xq26

?Insulin-dependent diabetes mellitus-2 (2) …....................................... 11 q

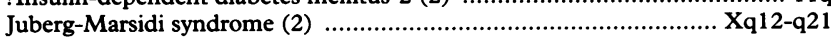

[Kininogen deficiency] (3) ....................................................... 3q26-qter

Kniest dysplasia (1) ......................................................... 12q13.11-q13.2

?Lactase deficiency, adult, 223100 (1) ........................................... 2q21

?Lactase deficiency, congenital (1) ............................................... 2q21

?actic acidosis due to defect in iron-sulfur cluster of complex I (1) .. 2q33-q34

Leiomatosis, diffuse (1) ........................................................... Xq22

Leukemia, acute, T-cell (2) .......................................................... 11 p13

Leukemia, chronic lymphocytic, B-cell (2) ...................................... 13q14

Leukemia, myeloid/lymphoid or mixed-lineage (2) ...........................11 q23

Leukemia/lymphoma, T-cell (3) .................................................. 14q11.2

Liposarcoma (1) ......................................................... 19p13.2-q13.3

Lymphoma, B-cell (2) .............................................................. 3q27

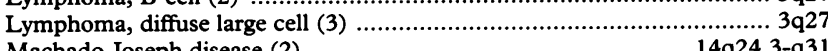

Machado-Joseph disease (2) ........................................... 14q24.3-q3

Macrocytic anemia refractory, of $5 \mathrm{q}$ - syndrome, 153550 (3) ….......... 5q31.1

[Macrothrombocytopenia] (1) ............................................... 7q1 1.2

Macular dystrophy (1) …................................................. 6p21.1-cen

Malignant hyperthermia susceptibility-1, 145600 (3) ......................19q13.1

Malignant hyperthermia susceptibility-2, 145600 (2) …............... 17q11.2-q24

Malignant melanoma, cutaneous (2) ........................................... $1 \mathrm{p} 36$

McCune-Albright polyostotic fibrous dysplasia, 174800 (1) ........... 20q13.2

Medullary thyroid carcinoma (3) ….......................................... 10q11.2

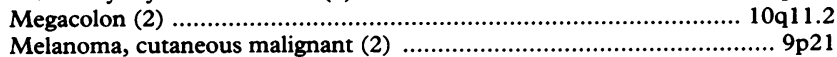


Table 2 - contd

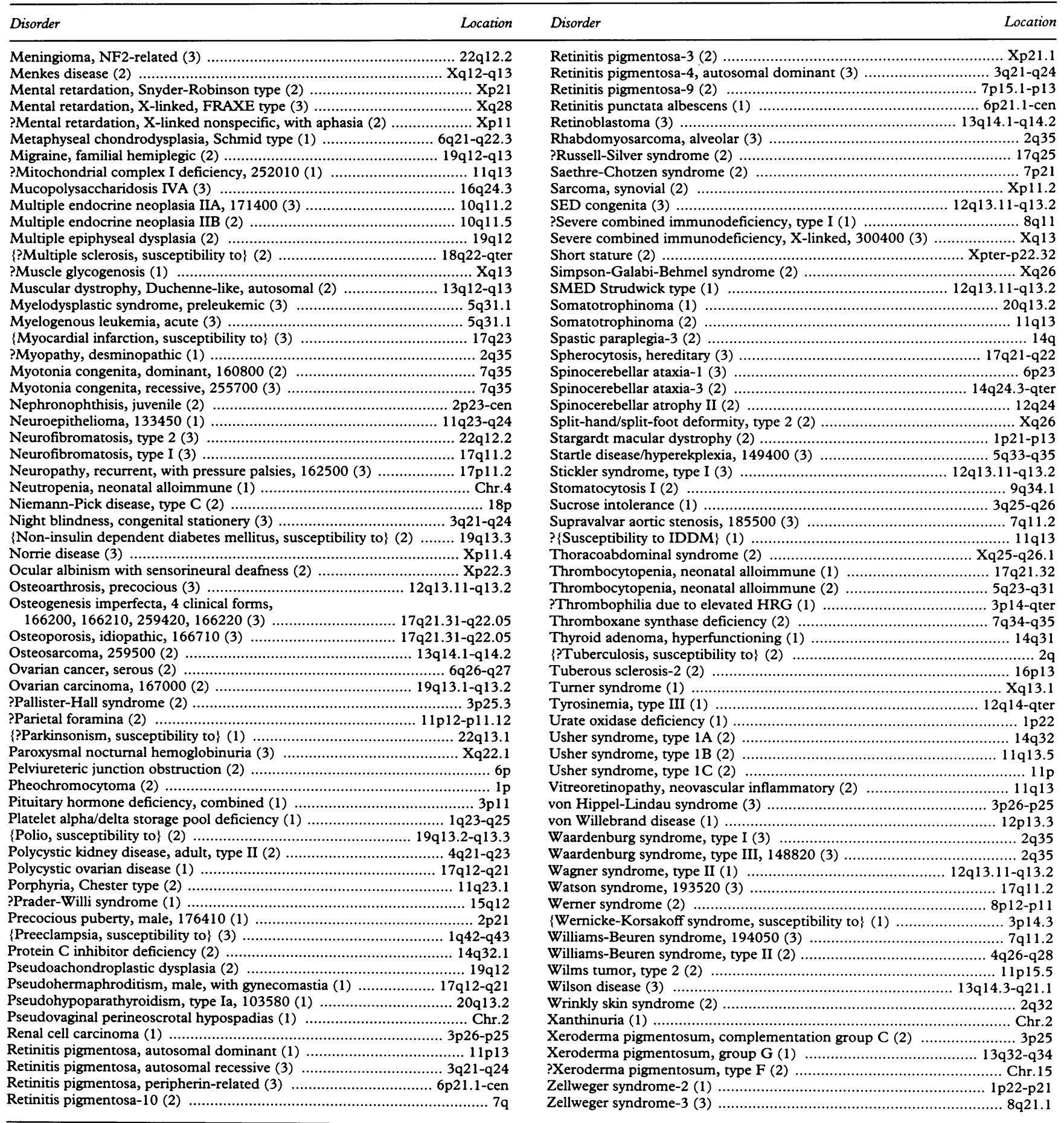

